\title{
Foreign Entry and Spillovers with Technological Incompatibilities in the Supply Chain*
}

\author{
Juan Carluccio ${ }^{\dagger}$ and Thibault Fally ${ }^{\ddagger}$
}

July 2012

\begin{abstract}
Does foreign entry improve host country productivity and welfare? Previous studies have looked at the role of backward linkages with domestic suppliers and their effects on domestic competitors. In this paper, we study how these externalities are affected by technological incompatibilities between foreign and domestic technologies. When foreign technologies require specialized inputs, some local suppliers self-select into production for multinational firms. A decrease in the cost of inputs compatible with the foreign technology has heterogeneous effects. It benefits foreign firms and the most productive downstream domestic firms that adopt the foreign technology, and negatively affects firms using the domestic technology. Technological incompatibilities reduce the welfare gains from openness to FDI, but this negative effect can be overcome by domestic technology adoption. The model's predictions are consistent with the stylized facts drawn from the empirical literature on FDI spillovers.
\end{abstract}

JEL: F23, O14.

\footnotetext{
${ }^{*}$ We are indebted to Thierry Verdier for helpful comments and suggestions. We also thank Maria Bas, Arnaud Costinot, Jonathan Eaton, Karolina Ekholm, Juan Carlos Hallak, Russell Hillberry, Wolfgang Keller, Kala Krishna, Jim Markusen, Peter Neary, Jerome Pouyet, Andres Rodriguez-Clare and James Tybout for helpful discussions, and seminar participants at Penn State University, University of Melbourne, University of Illinois at Urbana-Champaign, University of Nottingham, University of Barcelona, University of Modena, Paris School of Economics, Universidad de Buenos Aires and University of Hamburg. We are responsible for any remaining errors.

${ }^{\dagger}$ Banque de France and Paris School of Economics, 33 rue Croix-des-petis-champs, 75001 Paris, France. juan.carluccio@pse.ens.fr, +33677357305

${ }^{\ddagger}$ University of Colorado at Boulder, Department of Economics, 256 UCB, Boulder Colorado 80309-0256. fally@colorado.edu +13034926652.
} 


\section{Introduction}

The host country effects of Foreign Direct Investment (FDI) constitute a traditional concern in international and development economics. One of the consequences of the impressive surge in FDI flows in recent decades has been to bring this debate back to the fore. The current view of the impact of multinationals is optimistic, and the general feeling is that, in many circumstances, their arrival can significantly contribute to the development of destination economies. ${ }^{1}$

Among the potential channels through which FDI is thought to enhance the development of host economies, spillovers to domestic firms is often cited as a salient one. Nevertheless, we have a far from full understanding of the different channels through which these externalities might operate. Two main possibilities have been put forward in the literature. The first is that the introduction of foreign technologies in host countries through multinational production can provide technology adoption opportunities for local firms by such means as demonstration effects (Burstein and Monge-Naranjo, 2009) and labor turnover (Markusen and Ethier, 1996). ${ }^{2}$ The second possibility is that the presence of multinational firms increases the demand for intermediate goods and creates backward linkages to local suppliers. The strengthening of the supply chain could then result in forward linkages to local downstream producers in the form of lower input prices (Rodriguez-Clare, 1996; Markusen and Venables, 1999).

Our contribution focuses on the second of these channels. Previous studies generally overlook the possibility that technologies used by multinational firms require different intermediate goods to those used by domestic firms. In this paper, we show that accounting for such differences significantly alters the effect of inward FDI on domestic firms and welfare in the host economy. Entry by foreign firms induces changes in the supply chain to obtain inputs compatible with the foreign technology. These changes can have adverse effects on firms using inputs compatible with the domestic technology. The reconfiguration of the supply chain benefits foreign firms and can also trigger technology adoption by domestic firms. When technology adoption is costly, the effects of foreign entry on domestic firms are not uniform. In this case, foreign entry benefits the best firms and is detrimental to the low-productivity firms. Technological incompatibilities can thus generate complex interactions between vertical linkages and technology adoption decisions, with important implications for the effects of openness to FDI in terms of technology adoption, firm selection, output reallocation and welfare.

Empirical evidence finds that foreign firms tend to operate more advanced technologies that require specialized inputs. ${ }^{3}$ For example, in Slovakia, Volkswagen requires that all suppliers obtain VDA quality certificates, ${ }^{4}$ in accordance with the requirements of the German automotive industry (UNCTAD, 2001

\footnotetext{
${ }^{1}$ UNCTAD (2008) tracks the yearly number of changes in national regulations conducive to foreign investment. It reports an increase in the number of these changes from 77 in 1992 to 177 in 2006 with a peak of 270 in 2004 .

${ }^{2}$ The predominant role of multinational firms in knowledge creation is visible in aggregate statistics. Keller (2009) refers to data from the National Science Foundation showing that $83 \%$ of all manufacturing R\&D in the US was conducted by parents of US multinationals in 1999.

${ }^{3}$ In addition, econometric evidence shows that multinationals use more advanced technologies than domestic firms, for both developed and developing economies. See the surveys in Alfaro and Rodriguez-Clare (2004) and Barba-Navaretti and Venables (2004).

${ }^{4}$ Verband der Automobilindustrie.
} 
p. 157). Standards are also an important requisite for entry into the global supply chains in the food industry. UNCTAD (2007 p. 18) reports on the case of the European supermarket industry, where supermarkets require that suppliers, irrespective of country of origin, comply with private protocols on food safety standards, logistical requirements, and process documentation.

A compelling example that highlights the incompatibilities central to our analysis is provided by a recent case study by Javorcik et al. (2006) on the Mexican soaps, detergents and surfactants industry. When Mexico opened its borders to foreign investors, incoming US multinationals brought with them technologies and product formats that were previously unavailable locally (e.g. "compact formulas"). The report documents how suppliers catering for multinationals (some foreign-owned themselves) had to reformulate their inputs by substituting foreign standard ingredients with cheaper ingredients when catering for domestic producers. Moreover, Mexican detergent producers incurred substantial costs reformatting their products to introduce the foreign technology.

We model interactions between firms in two vertically related industries. Foreign firms enter the downstream industry and compete with domestic firms for local consumers. In the baseline model, all downstream producers - domestic and foreign - are assumed to source intermediate inputs locally. Given technological incompatibilities, suppliers make decisions about which type of intermediate inputs they will produce. Under the assumption that efficiency increases with the range of available intermediate varieties (Ethier, 1982), suppliers' production choices affect the relative efficiency (and relative costs) of the two technologies. The impact of these choices on downstream firms differs depending on which technology they use and can consequently affect their decision to adopt a technology. Conversely, foreign entry and technology adoption in the downstream industry affect the demand for inputs and the suppliers' technology choices. We look at firms with heterogeneous productivity to study the role of firms' capacities in technology adoption and spillovers. We embed the industry model into an occupational choice model - in the spirit of Lucas (1978) - where individuals have heterogeneous managerial abilities and choose whether to run firms or work as production workers. ${ }^{5}$

We study equilibria with free entry for all three types of firms - foreign, domestic suppliers and domestic downstream producers - and free technology choice for domestic firms in both industries. There are three different types of equilibria, depending on the extent of technology adoption by downstream entrepreneurs. In two opposite extremes, none or all of the domestic firms adopt the foreign technology. In intermediate equilibria, only the best entrepreneurs self-select into adopting the foreign technology.

Our results are presented in two ways. First, comparative statics show how technology adoption, input availability and foreign entry depend on structural parameters. We find that, when foreign entry costs are sufficiently low, equilibria necessarily involve technology adoption by domestic firms. ${ }^{6}$ In this case, a reduction in foreign entry costs induces more foreign entry and also a larger proportion of upgrading firms in upstream and downstream industries. Similarly, we find that a decrease in the cost of technology adoption induces more entry by foreign firms and fosters technology adoption in both

\footnotetext{
${ }^{5}$ Rodriguez-Clare (1996) and Burstein and Monge-Naranjo (2009) also use this formulation in contexts related to ours.

${ }^{6}$ In our model, a decrease in foreign firms' entry costs has the same effects as an increase in the relative productivity of foreign firms or an increase in the total mass of potential foreign entrants.
} 
upstream and downstream industries. This creates strong complementarities between foreign firms and the most productive domestic firms.

A second way to present our results is to investigate the relationship between the extent of foreign presence in the economy and the performance of domestic firms. Foreign presence can be observed by econometricians, but entry decisions by multinational firms are endogenous and depend upon profit opportunities. We study how changes in structural parameters, mainly the fixed entry cost for multinationals, simultaneously affect foreign presence and domestic firm variables. We construct two measures of foreign presence similar to those used by empirical studies: the relative number of foreign firms and their share in total industry sales. Our model explains positive correlations between foreign presence and the average labor productivity of suppliers, the share of domestic entrepreneurs adopting the foreign technology, and their productivity. It also generates a negative correlation between foreign presence and domestic firm survival.

This issue is the focus of an extensive empirical literature. ${ }^{7}$ We believe that our theory offers a plausible explanation for the mechanisms driving the reduced-form empirical studies. The literature delivers the following key messages. First, there is robust evidence of positive vertical spillovers: the presence of multinational firms tends to be associated with improvements in the productivity of local suppliers. Second, there is evidence of negative horizontal spillovers in the case of developing countries, and weak evidence of neutral or positive horizontal spillovers in the case of developed economies. Importantly, firm heterogeneity matters: only the productivity of firms with high absorptive capacity tends to be positively correlated with foreign presence. The correlation tends to be negative for firms with low absorptive capacity. Lastly, there is evidence of positive externalities between multinational firms consistent with our model.

We derive a simple measure of the gains from openness to FDI in our framework, inspired by the work of Arkolakis et al. (2012). We use empirically relevant parameters to quantify welfare gains depending on foreign presence, technological incompatibilities and technology adoption. Conditional on observed foreign presence, gains from FDI are substantially lower when intermediate goods are technologyspecific and no downstream domestic firms adopt the foreign technology. Conversely, welfare gains can be greater when a significant proportion of downstream domestic firms adopt the foreign technology.

Our paper contributes to a small, but growing body of formal literature studying backward linkages between multinational firms and local suppliers. The pioneering study in this area is by Rodriguez-Clare (1996), who develops a model in which multinationals source intermediate goods in a low-wage country: if the intensity with which they source local inputs - the "linkage coefficient" - is high enough, MNEs create higher net backward linkages that push the underdeveloped region out of the "bad" equilibrium. Markusen and Venables (1999) develop a similar intuition in an industrial organization approach that is closer to ours. As in the work of Rodriguez-Clare, the demand for inputs (backward linkages) created by foreign plants causes entry upstream. This exerts downward pressure on the costs of all downstream firms, generating a forward linkage. Domestic firms, more intensive users of local inputs, gain relatively more. A recent paper by Alfaro et al. (2009) expands on this literature to study the

\footnotetext{
${ }^{7}$ See the surveys in Gorg and Greenaway (2004), Lipsey (2002), and Alfaro and Rodriguez-Clare (2004).
} 
role of financial development in linkage creation. In all three papers, however, demand for intermediate goods from multinational firms is directed towards all local upstream firms (in addition to imports). This assumption contradicts evidence suggesting that multinationals tend to source from a small base of local suppliers, as presented by UNCTAD (2001) and OECD (2002) among others. By incorporating this key feature, we improve on this early work and provide a framework better suited to explain empirical results.

Our paper complements the work by Lin and Saggi (2007). These authors study a multinational firm's exclusive contracts with local suppliers in a model of a two-tier Cournot oligopoly, in which a foreign firm transfers technology to local suppliers. Exclusive contracts restrict technology transfers from the multinational firm to the group of exclusive suppliers, thus leaving domestic producers with a limited number of suppliers who do not benefit from the technology transfers. The framework we develop differs with respect to theirs. Crucial to our results, we allow for free entry and free technological choice for all types of firms in both industries. Our paper is also the first to explicitly model the role of firm heterogeneity. This unveils a role for different types of externalities between firms and yields additional predictions that are in line with the empirical evidence.

The rest of the paper is organized as follows. Section 2 presents the models set-up while Section 3 examines the different equilibria and comparative statics. Section 4 analyzes the welfare implications. In Section 5, we discuss a simple extension of the model allowing for trade in intermediate goods. Section 6 concludes.

\section{Set-up of the model}

We now develop a model of an economy composed of two vertically related industries. In the downstream industry, domestic and multinational firms compete to serve local consumers. In the upstream industry, intermediate goods are assumed to be produced only by local suppliers. We assume that these two industries face a competitive supply of labor and we normalize the wage to unity.

For the ease of reading, we henceforth denote all variables pertaining to the downstream industry in uppercase, as opposed to lowercase for upstream industry variables.

\section{Preferences}

Consumer preferences are assumed to be represented by the following standard CES utility function:

$$
U=\left(\int_{0}^{N} Q_{i}^{\rho} d i\right)^{\frac{1}{\rho}}
$$

We denote by $\sigma=\frac{1}{1-\rho}$ the constant elasticity of substitution between any two varieties of the final good. $N$ refers to the measure of all available varieties produced. If $E$ denotes total income spent in 
the economy, the demand curve for a firm producing variety $i$ is:

$$
Q_{i}=\left(\frac{P_{i}}{P}\right)^{-\sigma} \frac{E}{P}
$$

where $P_{i}$ is the price of variety $i$ and $P=\left(\int_{0}^{N} P_{i}^{1-\sigma} d i\right)^{\frac{1}{1-\sigma}}$ the price index of final goods.

\section{Production and technological incompatibilities}

There are two technologies for final good production, which we label the "D-technology" and the "Mtechnology". Throughout, we think of these two technologies as domestic and foreign. The total number of varieties produced in the economy is $N=N_{D}+N_{M}$ where the subscripts indicate the technology used to produce the varieties.

A central assumption is that intermediate goods are technology-specific. We call D-type inputs those required to produce using the D-technology and M-type inputs those produced for use with the M-technology. In both technologies, intermediate varieties are assumed to be horizontally differentiated and to enter final production as a CES composite, as in Ethier (1982).

The technology-specific production function used by the typical downstream firm $i$ is:

$$
Q_{i}=\Phi_{i} L_{i}^{1-\beta}\left(\int_{0}^{n_{T}} q_{T i j}^{\frac{\varepsilon-1}{\varepsilon}} d j\right)^{\frac{\beta \varepsilon}{\varepsilon-1}}
$$

where $L_{i}$ is the measure of workers employed by downstream firm $i, \Phi_{i}$ is the ability of firm $i, n_{T}$ is the range of input varieties specific to technology $\mathrm{T}, q_{\text {Tij }}$ is the quantity of input variety $j$ for technology $\mathrm{T}$ consumed by downstream firm $i$, and $\varepsilon>1$ is the elasticity of substitution between input varieties. In general, $\varepsilon$ may differ from the elasticity of substitution between final goods $\sigma$.

Parameter $\beta$ measures the importance of technology-specific inputs in production. It is a key parameter in our model and should be interpreted as a measure of technological incompatibilities. A natural alternative formulation would include a third category of inputs compatible with both technologies. In such a case, compatible inputs would play a neutral role in the model and, as in this version, all effects found would operate through the technology-specific inputs. ${ }^{8}$

This specification of technology aims to capture the idea that the division of labor enhances production efficiency (see Ciccone and Matsuyama, 1993). The larger the set of available intermediate varieties for a given technology, the lower the costs associated with the use of this technology. This property plays a key role in our analysis.

As the wage rate is set to unity, the price index for inputs for a firm producing under technology $\mathrm{T}$, which we label $\Lambda_{T}$, is given by:

$$
\Lambda_{T}=\left(\int_{0}^{n_{T}} p_{j T}^{1-\varepsilon} d j\right)^{\frac{\beta}{1-\varepsilon}}
$$

\footnotetext{
${ }^{8}$ To be more precise, with a free-entry condition in the compatible inputs industry, we would find that the mass of suppliers producing compatible inputs is constant and does not depend on foreign entry or technology adoption by other firms. Compatible inputs would thus play the same role as a numeraire.
} 
Upstream, $\lambda_{T}$ represents the quantity of labor required to produce one unit of the intermediate good with technology $T \in\{D, M\}$. The case in which the foreign technology is has higher labor productivity would correspond to $\lambda_{M}<\lambda_{D}$. Nevertheless, we will solve the model for the general case, without specifying a particular ranking of these parameters.

Relative variable costs associated with each of the two technologies, $\Lambda_{M} / \Lambda_{D}$, depend on the relative availability of specialized inputs $n_{M} / n_{D}$ :

$$
\frac{\Lambda_{M}}{\Lambda_{D}}=\left(\frac{\lambda_{M}^{1-\varepsilon}}{\lambda_{D}^{1-\varepsilon}} \frac{n_{M}}{n_{D}}\right)^{\frac{\beta}{1-\varepsilon}}
$$

As usual in monopolistic competition models, we assume that there is a large potential set of varieties of both intermediate and final goods, and that each firm produces a different variety.

\section{Managerial ability and occupational choice}

The economy is populated by a mass $L$ of individuals. As in Lucas (1978), individuals are heterogeneous in their managerial abilities and can become entrepreneurs in either industry or instead choose to work for other firms (in the upstream or downstream industries). ${ }^{9}$ A key difference between these occupations is that returns to managerial activities are given by firms' profits whereas wages are the same for all workers and determined in the labor market. More able individuals find becoming entrepreneurs more attractive. For simplicity, we consider that upstream firms are homogeneous and that ability matters only for managers of downstream firms. ${ }^{10}$

Managerial ability $\Phi$ is a continuous random variable drawn from a cumulative distribution $G(\Phi)$ with support $[1, \infty)$. We assume $G(\Phi)$ has the form of a Pareto distribution:

$$
G(\Phi)=1-\Phi^{-k}
$$

where the shape parameter $k$ is assumed to satisfy $k>\sigma-1$. This assumption yields tractable solutions while fitting the observed distributions of firm size well (see Axtell, 2001, and Helpman, Melitz and Yeaple, 2004). It has been used extensively in recent theoretical contributions (see the survey in Redding, 2011), hence allowing for a comparison of our results with the current literature.

We assume that downstream domestic managers can operate the domestic technology at no extra cost. However, they can produce with the M-technology upon payment of an additional fixed cost $F_{M}$ in terms of labor. This fixed cost does not depend on foreign presence. ${ }^{11}$

There is a mass $L^{*}$ of foreign entrepreneurs with the same ability distribution as the domestic entrepreneurs, $G(\Phi)$. Given its functional form, rescaling $L^{*}$ is equivalent to shifting the distribution

\footnotetext{
${ }^{9}$ Rodriguez-Clare (1996) and Burstein and Monge-Naranjo (2009) also use this formulation in contexts related to ours.

${ }^{10}$ This assumption avoids any complicated sorting of managers across industries. Heterogeneous suppliers are considered in previous versions of this paper and yield similar results (see Carluccio and Fally, 2008).

${ }^{11}$ Alternatively, we could assume that the presence of multinational firms affects the capacity to adopt foreign technologies through imitation or pure technology transfers. Here, we abstract from this direct effect and focus on how pecuniary externalities (competition and availability of inputs) affect the adoption of the foreign technology by domestic firms.
} 
(reflecting a different distribution of abilities for foreign entrepreneurs and domestic entrepreneurs).

\section{Equilibrium}

Equilibrium in the model is defined by the following system of equations:

$$
\begin{aligned}
\pi_{M} & =1 \\
\pi_{D} & =1 \\
\Pi_{D}\left(\Phi_{D}\right) & =1 \\
\Pi_{M}\left(\Phi_{M}\right) & =\Pi_{D}\left(\Phi_{M}\right)+F_{M} \\
\Pi_{M}\left(\Phi_{M N E}\right) & =F_{M N E}
\end{aligned}
$$

The first two equations are equilibrium conditions for the upstream industry. $\pi_{T}$ refers to upstream suppliers' profits using technology $T \in\{D, M\}$. At equilibrium with free entry, free occupational and free technology choice, profits associated with producing each type of input are equal to the opportunity cost $w=1$ of working as an employee. For each technology $T \in\{D, M\}$, profits in the upstream industry decrease with the number of suppliers $n_{T}$.

The last three equations are equilibrium conditions for the downstream industry. $\Pi_{T}(\Phi)$ refers to the profits made by downstream firms with ability $\Phi$ using technology $T \in\{D, M\}$. Downstream profits are monotonically increasing in managerial ability $\Phi$ (as we show in Section 3.2), whereas the returns to labor and to upstream managers are independent of managerial ability. Hence, the share of individuals becoming entrepreneurs, the share of entrepreneurs adopting the foreign technology and the share of foreign entrepreneurs entering the country are pinned down by the minimum value of ability that generates profits equal to the value of the relevant alternative. These are given by $\Phi_{D}, \Phi_{M}$ and $\Phi_{M N E}$ respectively and are implicitly defined by equations (5), (6) and (7).

An equilibrium is defined as a 5 -tuple $\left(n_{D}, n_{M}, \Phi_{D}, \Phi_{M}, \Phi_{M N E}\right)$ satisfying equations (3) to (7).

It is useful to construct an index $\tilde{N}_{T}$ representing the mass of firms using each technology $T \in$ $\{D, M\}$ weighted by their ability $\Phi$. The masses of firms depend on firm entry and technology adoption decisions as reflected by the thresholds:

$$
\begin{array}{ll}
\widetilde{N}_{M}\left(\Phi_{M}, \Phi_{M N E}\right) & =L \int_{\Phi_{M}}^{\infty} \Phi^{\sigma-1} d G(\Phi)+L^{*} \int_{\Phi_{M N E}}^{\infty} \Phi^{\sigma-1} d G(\Phi) \\
\widetilde{N}_{D}\left(\Phi_{D}, \Phi_{M}\right) & =L \int_{\Phi_{D}}^{\Phi_{M}} \Phi^{\sigma-1} d G(\Phi)
\end{array}
$$

The intuition of the model is best developed in three steps. We first analyze the upstream industry, taking entry in the downstream industry as given. We then study the downstream industry, taking the upstream configuration (input prices) as given. In Section 3.3, we examine joint equilibria for both industries. Through to Section 3.4, we study equilibria holding expenditure $E$ fixed. In Section 3.4, we study the general equilibrium by considering a labor market clearing condition and solving for $E .^{12}$

\footnotetext{
${ }^{12}$ As we discuss in section $3.4, E$ proves to be independent of foreign entry and technology adoption.
} 


\subsection{Equilibrium in the upstream industry}

Using the functional forms for demand and technology, we obtain the following expressions for equations (3) and (4):

$$
\begin{aligned}
& \pi_{M}=\frac{\beta \rho}{\varepsilon} \frac{E}{n_{M}} \frac{\widetilde{N}_{M} \Lambda_{M}^{1-\sigma}}{\widetilde{N}_{D} \Lambda_{D}^{1-\sigma}+\widetilde{N}_{M} \Lambda_{M}^{1-\sigma}} \\
& \pi_{D}=\frac{\beta \rho}{\varepsilon} \frac{E}{n_{D}} \frac{N_{D} \Lambda_{D}^{1-\sigma}}{\widetilde{N}_{D} \Lambda_{D}^{1-\sigma}+\widetilde{N}_{M} \Lambda_{M}^{1-\sigma}}
\end{aligned}
$$

The measure of suppliers self-selecting into each technology depends positively on the demand for each type of input (itself determined by final good demand). Combining the two equations, we find that the relative measure of suppliers equals the relative share of technologically differentiated varieties in consumption: $\frac{n_{M}}{n_{D}}=\frac{\widetilde{N}_{M} \Lambda_{M}^{1-\sigma}}{\widetilde{N}_{D} \Lambda_{D}^{1-\sigma}}$. The right-hand side of this equation is, however, itself endogenous to the relative number of suppliers. As described in equation (2), the price index of inputs $\Lambda_{T}$ for each technology directly depends on the number of suppliers. Incorporating (2), we find the following solution for the total and relative number of suppliers:

$$
\begin{aligned}
n_{M}+n_{D} & =\frac{\beta \rho E}{\varepsilon} \\
\frac{n_{M}}{n_{D}} & =\left(\frac{\lambda_{M}^{1-\varepsilon}}{\lambda_{D}^{1-\varepsilon}}\right)^{\frac{\widetilde{\beta}}{1-\widetilde{\beta}}}\left(\frac{\widetilde{N}_{M}}{\widetilde{N}_{D}}\right)^{\frac{1}{1-\widetilde{\beta}}} \\
\text { with: } & \widetilde{\beta}=\beta \cdot \frac{\sigma-1}{\varepsilon-1}
\end{aligned}
$$

It is then easy to recover the solution for $n_{D}$ and $n_{M}$ : given the relative mass of downstream plants, there is a unique equilibrium in the upstream industry. The coexistence of different technologies in the upstream industry requires the elasticity of substitution between inputs to be sufficiently large: $\varepsilon-1>\beta(\sigma-1)$. This condition is assumed throughout and satisfied when $\varepsilon$ and $\sigma$ are similar. Equilibrium in the upstream industry is then uniquely determined by the relative mass of downstream firms $\frac{\widetilde{N}_{M}}{\widetilde{N}_{D}}$ using each technology. ${ }^{13}$

We can then derive a relationship between the relative cost of inputs and the relative masses of firms producing final goods using each technology:

$$
\frac{\Lambda_{M}^{1-\sigma}}{\Lambda_{D}^{1-\sigma}}=\left(\frac{\lambda_{M}^{1-\varepsilon}}{\lambda_{D}^{1-\varepsilon}} \frac{\widetilde{N}_{M}}{\widetilde{N}_{D}}\right)^{\frac{\widetilde{\beta}}{1-\widetilde{\beta}}}
$$

$\frac{\Lambda_{M}^{1-\sigma}}{\Lambda_{D}^{1-\sigma}}>1$ means the M-technology is more advantageous. ${ }^{14}$ In equilibrium, the relative cost advantage of the M-technology depends positively on its relative productivity $\frac{\lambda_{M}^{1-\varepsilon}}{\lambda_{D}^{1-\varepsilon}}$ : the more efficient the

\footnotetext{
${ }^{13}$ In an extreme case where the mass of downstream firms $\widetilde{N}_{T}$ is zero for a particular technology $T$, no supplier adopts this technology. The mass of suppliers for the alternative technology is $\frac{\beta \rho E}{\varepsilon}$.

${ }^{14}$ Throughout the rest of the paper we refer to $\frac{\Lambda_{M}^{1-\sigma}}{\Lambda_{D}^{1-\sigma}}>1$ as the relative cost advantage of the M-technology. Strictly speaking, this ratio refers only to variable costs. We omit the word variable for simplicity.
} 
technology $\mathrm{M}$ is, the larger the proportion of suppliers choosing to produce with it. Most importantly, this equilibrium relationship also shows that the higher the relative mass of firms using technology M, the lower the relative costs of M-type inputs. Higher demand for M-type inputs (backward linkages) prompts suppliers to produce varieties of the M-type. Through backward linkages, downstream industrial structure determines the upstream industry configuration. Because of the love for variety in inputs, this in turn favors the cost advantage of the M-technology, generating a forward linkage. Because of the incompatibility of both technologies, these pecuniary externalities are positive among firms using the foreign technology and negative towards firms using the domestic one. The exponent $\frac{\widetilde{\beta}}{1-\widetilde{\beta}}$ plays an important role as the elasticity determining the strength of these forces. It depends positively on $\beta$ : the larger share of technology-specific inputs in final good production the stronger the reaction of the upstream industry to changes in the downstream industry. It also depends negatively on $\varepsilon$ (which is inversely related to love for variety in inputs) and positively on $\sigma$ (which is inversely related to love for variety in final goods).

\subsection{Equilibrium in the downstream industry}

In this subsection, we treat the number of suppliers (and thus the input price index) in each technology as given and characterize the equilibrium in the downstream industry. Profits generated by the typical downstream plant using technology $\mathrm{T}$ with an ability draw $\Phi_{i}$ can be expressed as:

$$
\Pi_{T}\left(\Phi_{i}\right)=\frac{E \rho^{\sigma-1}}{\sigma} \frac{\Phi_{i}^{\sigma-1} \Lambda_{T}^{1-\sigma}}{P^{1-\sigma}}
$$

From equation (11), it is apparent that profits are monotonically increasing in ability $\Phi_{i}$. Since the earnings of suppliers and workers are independent of managerial ability, there is an ability cutoff $\Phi_{D}$ such that individuals with parameter $\Phi_{i}>\Phi_{D}$ choose to run downstream firms (equation 5). Entrepreneurs decide to take on the foreign technology provided that profits made with the M-technology $\Pi_{M}(\Phi)$ exceed profits earned with the D-technology $\Pi_{D}(\Phi)$, plus the fixed costs of technology adoption $F_{M}$. There exists a second cutoff $\Phi_{M}$ such that the domestic entrepreneur with ability $\Phi_{M}$ is indifferent between both technologies (equation 6).

Multinationals only operate the M-technology. They enter the host country to serve the local market as long as expected profits are positive (equation 7). Foreign entry is costly: it requires a fixed cost of $F_{M N E}$ units of (local) labor. It is straightforward to show that there is a strictly positive mass of foreign firms entering the domestic market for any finite value of $F_{M N E}\left(F_{M N E}=\infty\right.$ corresponds to a situation with no foreign firms, which we refer to as "autarky" in Section 4).

The relative cost advantage of operating the M-technology plays a key role in determining entry and technology adoption decisions. When $\frac{\Lambda_{M}^{1-\sigma}}{\Lambda_{D}^{1-\sigma}}<1$, the M-technology is relatively more expensive to use, and all domestic entrepreneurs choose to use the D-technology. When, however, the advantage of operating the M-technology is large enough, all entrepreneurs abandon the domestic technology. Formally, this requires the cost advantage to be large enough with respect to the fixed costs of technology

adoption, $\frac{\Lambda_{M}^{1-\sigma}}{\Lambda_{D}^{1-\sigma}}>\left(1+F_{M}\right)$. For values of $\frac{\Lambda_{M}^{1-\sigma}}{\Lambda_{D}^{1-\sigma}}$ in between these two extreme values, there exist mixed 
equilibria with positive shares of domestic entrepreneurs operating each technology.

We present here the expressions for the more general latter case, and we relegate the other two to the appendix. When $1<\frac{\Lambda_{M}^{1-\sigma}}{\Lambda_{D}^{1-\sigma}}<\left(1+F_{M}\right)$, solving from the equilibrium conditions yields the following expressions for the thresholds:

$$
\begin{aligned}
\Phi_{D} & =\left(\frac{k \sigma}{k-(\sigma-1)} \frac{L}{E}\right)^{\frac{1}{k}}\left[1+F_{M}^{1-\frac{k}{\sigma-1}}\left(\frac{\Lambda_{M}^{1-\sigma}}{\Lambda_{D}^{1-\sigma}}-1\right)^{\frac{k}{\sigma-1}}+\frac{L^{*}}{L} F_{M N E}^{1-\frac{k}{\sigma-1}}\left(\frac{\Lambda_{M}^{1-\sigma}}{\Lambda_{D}^{1-\sigma}}\right)^{\frac{k}{\sigma-1}}\right]^{\frac{1}{k}} \\
\Phi_{M}^{\sigma-1} & =\frac{\Lambda_{D}^{1-\sigma}}{\Lambda_{M}^{1-\sigma}-\Lambda_{D}^{1-\sigma}} \cdot F_{M} \Phi_{D}^{\sigma-1} \\
\Phi_{M N E}^{\sigma-1} & =\frac{\Lambda_{D}^{1-\sigma}}{\Lambda_{M}^{1-\sigma}} \cdot F_{M N E} \Phi_{D}^{\sigma-1}
\end{aligned}
$$

The survival threshold in equation (12) decreases with the fixed cost of technology adoption, the fixed cost of foreign entry, and the cost advantage of the M-technology. The probability that an entrant survives $\left(\Phi_{D}^{-k}\right)$ is proportional to the share of consumption for the goods produced using the D-technology, given by the inverse of the term in brackets. As shown in equations (13) and (14), the relative thresholds of technology adoption and foreign entry are simple functions of the relative cost of inputs and the fixed costs. Higher technology adoption costs imply a greater minimum ability for technology adoption to be profitable. Similarly, higher fixed costs of foreign entry induce a higher ability threshold for foreign entrepreneurs to break even. Lastly, both thresholds are decreasing functions of the cost advantage of the M-technology. These results hold for both the ratio of each of the thresholds to $\Phi_{D}$ and for their absolute values.

The three thresholds completely characterize the mass of downstream firms $\left(\tilde{N}_{D}, \widetilde{N}_{M}\right)$ as a function of input costs $\left(\Lambda_{D}, \Lambda_{M}\right)$. Using the Pareto distribution properties and the expressions derived above, we obtain the relative masses of firms $\frac{\widetilde{N}_{M}}{N_{D}}$ as a function of the relative cost of intermediates $\frac{\Lambda_{M}}{\Lambda_{D}}$ :

$$
\frac{\widetilde{N}_{M}}{\widetilde{N}_{D}}=\frac{\left(\frac{\Lambda_{M}^{1-\sigma}}{\Lambda_{D}^{1-\sigma}}-1\right)^{\frac{k}{\sigma-1}-1} F_{M}^{1-\frac{k}{\sigma-1}}+\frac{L^{*}}{L}\left(\frac{\Lambda_{M}^{1-\sigma}}{\Lambda_{D}^{1-\sigma}}\right)^{\frac{k}{\sigma-1}-1} F_{M N E}^{1-\frac{k}{\sigma-1}}}{1-\left(\frac{\Lambda_{M}^{1-\sigma}}{\Lambda_{D}^{1-\sigma}}-1\right)^{\frac{k}{\sigma-1}-1} F_{M}^{1-\frac{k}{\sigma-1}}}
$$

The numerator reflects the weighted mass of firms operating the M-technology: domestic firms upgrading technology and foreign firms. The denominator is the fraction of domestic firms using the domestic technology.

\subsection{Joint equilibrium in upstream and downstream industries}

As described in Section 3.1, an equilibrium in the upstream industry is characterized by a duplet of supplier masses $\mathbf{n}=\left(n_{D}, n_{M}\right)$ satisfying the supplier free entry conditions (3) and (4). Equations (9) and (8) describe how to uniquely solve for $\mathbf{n}$ as a function of the relative mass of downstream firms, 
and it would be straightforward to rewrite it as a function of a triplet of productivity thresholds $\mathbf{\Phi}=\left(\Phi_{D}, \Phi_{M}, \Phi_{M N E}\right)$. Hence, equilibrium in the upstream industry can be described as a function

$$
\mathbf{n}=\mathbf{n}_{u p}(\boldsymbol{\Phi})
$$

In turn, as described in Section 3.2, an equilibrium in the downstream industry is characterized by $\mathbf{\Phi}=\left(\Phi_{D}, \Phi_{M}, \Phi_{M N E}\right)$ satisfying the free entry conditions in the downstream industry (5), (6) and (7). Equations (12), (13) and (14) uniquely solve for $\boldsymbol{\Phi}$ as a function of the relative input price index and, given the definition of the input price index, it is straightforward to rewrite it as a function of the mass of suppliers $\mathbf{n}$. Hence, equilibrium in the downstream industry can be described as a function

$$
\mathbf{\Phi}=\boldsymbol{\Phi}_{\text {down }}(\mathbf{n})
$$

We define a joint equilibrium as a vector $(\mathbf{n}, \boldsymbol{\Phi})=\left(n_{D}, n_{M}, \Phi_{D}, \Phi_{M}, \Phi_{M N E}\right)$ that satisfies all freeentry conditions (3), (4), (5), (6) and (7). Equivalently, a joint equilibrium is characterized by $(\mathbf{n}, \boldsymbol{\Phi})$ such that $\mathbf{\Phi}=\boldsymbol{\Phi}_{\text {down }}(\mathbf{n})$ and $\mathbf{n}=\mathbf{n}_{u p}(\boldsymbol{\Phi})$ are simultaneously satisfied.

In general, there is no unique joint equilibrium. While equilibrium in one industry is unique for any given configuration of the other industry, there is more than one solution satisfying both equations at the same time. This feature is common to many models of vertical linkages with increasing returns to scale, including Rodriguez-Clare (1996), Markusen and Venables (1999), and Ciccone and Matsuyama (1996). As in some of these studies, we find that some of these equilibria are unstable as defined in the following:

Definition A stable equilibrium is defined as a vector $(\mathbf{n}, \boldsymbol{\Phi})=\left(n_{D}, n_{M}, \Phi_{D}, \Phi_{M}, \Phi_{M N E}\right)$ such that:

i) $\boldsymbol{\Phi}=\boldsymbol{\Phi}_{\text {down }}(\mathbf{n})$ and $\mathbf{n}=\mathbf{n}_{\text {up }}(\boldsymbol{\Phi})$, i.e. all free-entry conditions are satisfied.

ii) For any vector $\mathbf{n}^{\prime}$ in a neighborhood of $\mathbf{n}, \lim _{t \rightarrow \infty}\left(\mathbf{n}_{u p} \circ \boldsymbol{\Phi}_{\text {down }}\right)^{t}\left(\mathbf{n}^{\prime}\right)=\mathbf{n}$.

iii) For any vector $\boldsymbol{\Phi}^{\prime}$ in a neighborhood of $\boldsymbol{\Phi}, \lim _{t \rightarrow \infty}\left(\boldsymbol{\Phi}_{\text {down }} \circ \mathbf{n}_{u p}\right)^{t}\left(\boldsymbol{\Phi}^{\prime}\right)=\boldsymbol{\Phi}$.

A joint equilibrium that is not "stable" is defined as "unstable". A small deviation from an unstable equilibrium can drive the economy away from the initial equilibrium due to successive adjustments in the downstream and upstream industries. Conversely, "stable" equilibria have the property whereby firms' decisions following a small deviation take the economy back to the original equilibrium. In line with previous work (e.g. Markusen and Venables, 1999), we focus our analysis on stable equilibria. ${ }^{15}$ If condition i) is satisfied, then conditions ii) and iii) are formally equivalent given that both functions $\boldsymbol{\Phi}_{\text {down }}($.$) and \mathbf{n}_{u p}($.$) are continuous. In other words, we could define stability depending on the effect$ of deviations in either the downstream or upstream industries: both definitions would be equivalent in our framework.

\footnotetext{
${ }^{15}$ A rigorous treatment of stability would call for a dynamic setting describing the evolution of firm entry and technological choice depending on present and future profits. Such a treatment is beyond the scope of this paper. However, our simple definition of "stability" is sufficient to rule out equilibria where comparative statics would be counter-intuitive and to focus on a class of equilibria where comparative statistics are fairly homogeneous.
} 
There are three types of equilibria depending on the extent of technology adoption in the downstream industry. A first type of equilibria (type 1) is characterized by no technology adoption by downstream domestic firms. This occurs when $\frac{\Lambda_{M}^{1-\sigma}}{\Lambda_{D}^{1-\sigma}}<1$, even if there is entry by foreign firms in the downstream market. A second type of equilibria (type 2) is characterized by a positive fraction of downstream domestic firms adopting the foreign technology. This occurs when there is a cost advantage $\frac{\Lambda_{M}^{1-\sigma}}{\Lambda_{D}^{1-\sigma}}>1$ of using M-type inputs. A third type of equilibria (type 3) is characterized by all firms using the foreign technology. The following proposition summarizes how parameter values affect the existence of each type of equilibria:

Proposition 1 Assuming $\frac{\beta k}{\varepsilon-1}<1$, the following statements hold:

i) There can be at most one stable equilibrium with no technology adoption (type 1). A necessary and sufficient condition for the existence of such an equilibrium is: $F_{M N E}^{\frac{k}{\sigma-1}-1}>\frac{\lambda_{M}^{1-\varepsilon}}{\lambda_{D}^{1-\varepsilon}} \frac{L^{*}}{L}$.

ii) There can be at most one stable equilibrium with a subset of domestic firms adopting the foreign technology (type 2). A necessary (but not sufficient) condition for the existence of such an equilibrium is: $F_{M N E}^{\frac{k}{\sigma-1}-1}>\frac{\lambda_{M}^{1-\varepsilon}}{\lambda_{D}^{1-\varepsilon}} \frac{L^{*}}{L}\left(1+F_{M}\right)^{-\frac{(\varepsilon-1)-\beta k}{\beta(\sigma-1)}}$.

iii) For any parameter values there exists a unique stable equilibrium with all domestic firms adopting the foreign technology (type 3).

There is no stable equilibrium with the two technologies coexisting (types 1 and 2) if $\frac{\beta k}{\varepsilon-1}>1$ (see appendix). Hence, throughout we focus on the case where $\frac{\beta k}{\varepsilon-1}<1 .{ }^{16}$

Proposition 1 shows that multiplicity arises in general, except when the fixed cost of foreign entry is sufficiently low. ${ }^{17}$ As described in point i), large values of the fixed cost of foreign entry induce entry of a mass of foreign firms that is insufficient to trigger foreign technology adoption (type-1 equilibrium). This case is fully tractable (expressions in appendix), and both $\frac{\Lambda_{M}^{1-\sigma}}{\Lambda_{D}^{1-\sigma}}$ and $\frac{\widetilde{N}_{M}}{\widetilde{N}_{D}}$ are decreasing in $F_{M N E}$.

As described in point iii), any set of parameter values are compatible with an equilibrium featuring full technology adoption: $\widetilde{N}_{D}=n_{D}=0$. This case is also fully tractable (expressions in appendix). This full-technology-adoption equilibrium (type 3 ) is the only possible outcome for low values of the fixed cost of foreign entry. The condition $F_{M N E}^{\frac{k}{\sigma-1}-1}<\frac{\lambda_{M}^{1-\varepsilon}}{\lambda_{D}^{1-\varepsilon}} \frac{L^{*}}{L}\left(1+F_{M}\right)^{-\frac{(\varepsilon-1)-\beta k}{\beta(\sigma-1)}}$ is sufficient to rule out equilibria with less than full technology adoption. The condition is more likely to be met the lower $F_{M}$ : when the cost of technology adoption is low, lower multinational entry is required to trigger full technology adoption.

\footnotetext{
${ }^{16}$ Evidence on productivity dispersion suggests that this condition is likely to be satisfied. $\beta$ reflects the share of technology-specific inputs in production, which is likely to be less than one half, and the Pareto coefficient for the dispersion of sales $\frac{k}{\sigma-1}$ is generally less than 2. Moreover, we could expect $\sigma$ and $\varepsilon$ to be relatively close.

${ }^{17}$ To be more precise, the proposition gives conditions on the fixed cost of foreign entry with respect to the technological advantage of the M-technology and the relative measures of foreign entrepreneurs. As already stated, given the functional form of the distribution of abilities, $\frac{L^{*}}{L}$ also represents the distance between the support of foreign and local ability distributions.
} 
The remainder of this section focuses on cases with intermediate values of $F_{M N E}$ which feature equilibria where domestic firms self-select into different technologies (type 2). This case is not analytically tractable. Nevertheless, comparative statics and a detailed qualitative description of joint equilibria are possible.

Figure 1 provides an example, with $\log \left(\frac{\widetilde{N}_{M}}{\widetilde{N}_{D}}\right)$ on the Y-axis and $\log \left(\frac{\Lambda_{M}^{1-\sigma}}{\Lambda_{D}^{1-\sigma}}\right)$ on the X-axis. ${ }^{18}$ The "upstream" curve refers to equation (10) while the "downstream" curve refers to equation (15) when $\frac{\Lambda_{M}^{1-\sigma}}{\Lambda_{D}^{1-\sigma}}>1$ and becomes linear when $\frac{\Lambda_{M}^{1-\sigma}}{\Lambda_{D}^{1-\sigma}}<1$. Although the two curves may intersect more than once, their relative slopes help determine whether an equilibrium is stable or not. The slope of the downstream curve reflects how the downstream industry (particularly the relative mass of firms using the foreign technology on the $\mathrm{Y}$-axis) reacts to changes in the relative availability of inputs (X-axis). A steeper curve means that a deviation in the upstream equilibrium has a larger impact on the downstream industry. Conversely, the slope of the upstream curve is inversely related to how the upstream industry reacts to changes in the downstream industry, i.e. the strength of backward linkages. ${ }^{19}$ A flatter upstream curve means that a deviation in the downstream equilibrium (relative mass of firms on the Y-axis) has a larger impact on the relative mass of suppliers (on the $\mathrm{X}$-axis). In line with the formal definition, a stable equilibrium corresponds to an intersection where the upstream curve is steeper than the downstream curve. Hence, label "E" on the graph refers to a stable equilibrium and label "U" to an unstable equilibrium.

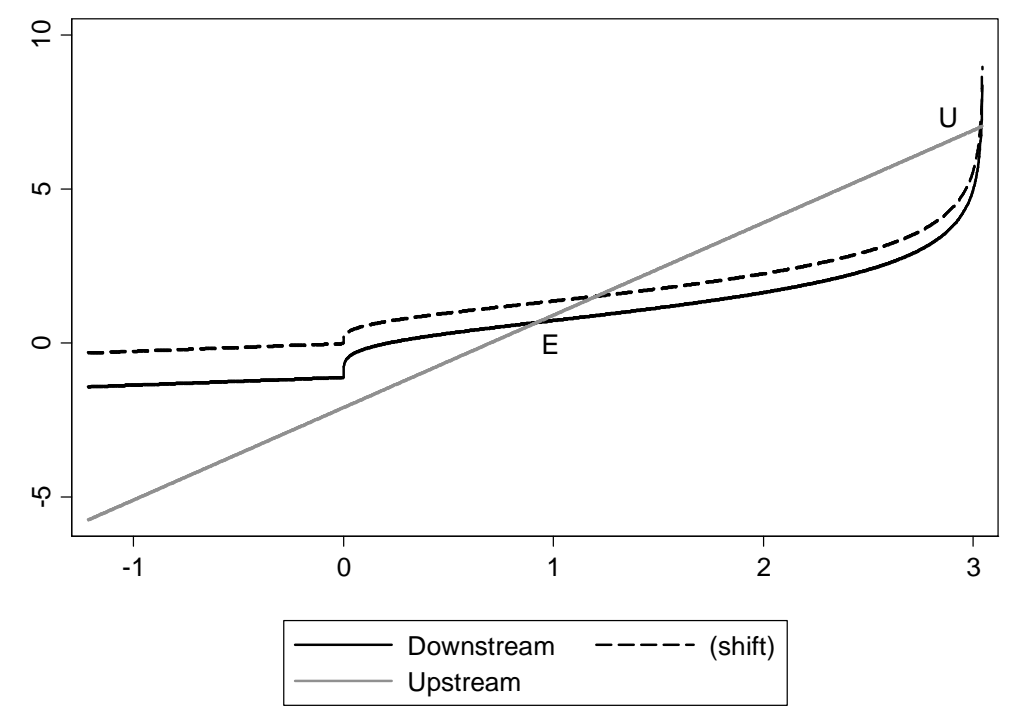

Figure 1: Equilibrium with partial technology adoption

\footnotetext{
${ }^{18}$ The figure was constructed with the following parameter values: $\frac{k}{\sigma-1}=1.25, \beta=0.25, \sigma=\varepsilon=4, \frac{\lambda_{D}}{\lambda_{M}}=2$, $\frac{L^{*}}{L} F_{M N E}^{1-\frac{k}{\sigma-1}}=0.33$ and $F_{M}=20$. The dotted line (shift) has $\frac{L^{*}}{L} F_{M N E}^{1-\frac{k}{\sigma-1}}=1$. Under this parameter configuration, no type 1 equilibrium arises. The choices for $\frac{k}{\sigma-1}, \beta$ and $\sigma$ are motivated by existing studies, as discussed in Section 4 .

${ }^{19}$ The slope of the upstream curve is $\frac{1-\widetilde{\beta}}{\widetilde{\beta}}$. The larger the share of specific inputs in production, the flatter it is.
} 
Proposition 1 states that there is at most one stable equilibrium of this type. In addition, a stable equilibrium with partial technology adoption satisfies the comparative statics given in the following proposition:

Proposition 2 In a stable equilibrium with partial technology adoption (type 2), a decrease in the foreign entry cost $F_{M N E}$ leads to:

i) A larger mass $n_{M}$ of suppliers using the foreign technology.

ii) A smaller mass $n_{D}$ of suppliers using the domestic technology.

iii) A higher ability threshold $\Phi_{D}$ of domestic firms survival.

iv) A lower ability threshold $\Phi_{M N E}$ of foreign firm entry.

v) A lower ability threshold $\Phi_{M}$ of technology adoption.

The larger $\beta$, the stronger these effects. A decrease in the technology adoption cost $F_{M}$ has the same qualitative effects as $F_{M N E}$.

A lower foreign entry cost induces further adoption of the foreign technology in both the upstream and downstream industries. Graphically, this can be illustrated by an upward shift of the downstream curve in Figure 1 (this corresponds to equation 15 where the right-hand side is negatively related to $\left.F_{M N E}\right)$. In a stable equilibrium where the slope of the downstream curve is not as steep as the upstream curve, E moves right and up, which corresponds to a higher relative availability of M-type inputs (larger measure of suppliers of M-type inputs and smaller measure of suppliers of D-type inputs) and a larger relative mass of downstream firms using the M-technology.

A lower cost of inputs compatible with the foreign technology induces more foreign firms to enter (equation 14 combined with 12), and more domestic firms to adopt the foreign technology (equation 13 combined with 12). This causes fewer domestic firms to survive (equation 12). These effects add to the direct effect of the foreign entry cost on $\Phi_{M N E}$ and $\Phi_{D}$ (i.e. holding the price of inputs constant).

This case is useful to study the role of technological incompatibilities in our framework. When these are relatively small ( $\beta$ close to zero), the upstream curve rotates to become more vertical. A change in the downstream curve does not affect the relative availability of inputs. The effect of the cost of foreign entry on the proportion of domestic firms adopting the foreign technology is very small ( $\frac{\Phi_{M}}{\Phi_{D}}$ remains constant). When $\beta$ is large, a shift in the downstream curve induces larger changes in the relative availability of inputs, thus triggering a greater change in technology adoption (graphically, the upstream curve rotates to become more horizontal as $\beta$ increases). A similar role is played by the coefficient of the productivity distribution $k$ : a larger value (meaning less dispersion) makes the slope of the downstream curve steeper (equation 15): technology adoption and foreign entry are more sensitive to input costs.

Interestingly, a decrease in the domestic technology adoption cost $F_{M}$ has qualitatively similar effects. While encouraging foreign entry triggers domestic technology adoption, the converse is also true: facilitating technology adoption induces foreign entry. The model hence highlights complementarities between innovation and FDI policies which, to the best of our knowledge, had not been investigated by previous studies. 


\section{Foreign presence and domestic firms' performance}

We now use our model to study the relationship between observed foreign presence (FP) and the performance of domestic firms. We derive two measures of foreign presence. First, we define FPN as the ratio of the number of foreign firms to domestic firms:

$$
F P N=\frac{L^{*} \Phi_{M N E}^{-k}}{L \Phi_{D}^{-k}}=\frac{L^{*} F_{M N E}^{-\frac{k}{\sigma-1}}}{L}\left(\frac{\Lambda_{M}^{1-\sigma}}{\Lambda_{D}^{1-\sigma}}\right)^{\frac{k}{\sigma-1}}
$$

Second, we define FPS as the ratio of foreign to domestic firm sales:

$$
F P S=\frac{L^{*} F_{M N E} \Phi_{M N E}^{-k}}{L \Phi_{D}^{-k}+L F_{M} \Phi_{M}^{-k}}=\frac{L^{*}}{L} \frac{F_{M N E}^{1-\frac{k}{\sigma-1}}\left(\frac{\Lambda_{M}^{1-\sigma}}{\Lambda_{D}^{1-\sigma}}\right)^{\frac{k}{\sigma-1}}}{1+F_{M}^{1-\frac{k}{\sigma-1}}\left(\frac{\Lambda_{M}^{1-\sigma}}{\Lambda_{D}^{1-\sigma}}-1\right)^{\frac{k}{\sigma-1}}}
$$

The above formulae are for the case in which both technologies coexist in equilibrium (type 2 above). When there is no technology adoption by domestic firms, we have $F P S=\frac{L^{*}}{L} F_{M N E}^{1-\frac{k}{\sigma-1}}\left(\frac{\Lambda_{M}^{1-\sigma}}{\Lambda_{D}^{1-\sigma}}\right)^{\frac{k}{\sigma-1}}$. With full technology adoption, FPN and FPS become $\frac{L^{*}}{L}\left(\frac{F_{M N E}}{1+F_{M}}\right)^{-\frac{k}{\sigma-1}}$ and $\frac{L^{*}}{L}\left(\frac{F_{M N E}}{1+F_{M}}\right)^{1-\frac{k}{\sigma-1}}$ respectively.

These measures are endogenous in our model. Both are decreasing in the foreign entry costs $F_{M N E}$ and increasing in the relative exogenous efficiency of the foreign technology $\frac{\lambda_{M}^{1-\varepsilon}}{\lambda_{D}^{1-\varepsilon}}$, and the ratio of the minimum ability of foreign entrepreneurs to the minimum ability of domestic entrepreneurs (as given by $\left.\frac{L^{*}}{L}\right){ }^{20}$ In equilibria with partial technology adoption, a reduction in $F_{M}$ unambiguously raises unweighted foreign presence FPN. The effect of $F_{M}$ on FPS is ambiguous. It increases the relative masses of firms using the foreign technology and benefits foreign firms. However, technology adoption by domestic firms increases competition, which could reduce foreign presence weighted by sales. With full technology adoption, only the latter effect comes into play, and reductions in $F_{M}$ decrease both measures of foreign presence.

Using the results derived in the previous subsection, we can study how changes in the parameters of the model simultaneously affect foreign presence and other variables of interest. Assuming $\lambda_{M}<\lambda_{D}$ we find:

Proposition 3 In equilibria with partial technology adoption, differences in foreign entry costs $F_{M N E}$ across industries or time generate:

i) a positive correlation between FP and the share of suppliers adopting the foreign technology;

ii) a negative correlation between FP and the availability of D-tech inputs;

iii) a positive correlation between FP and the fraction of domestic firms adopting the M-technology;

iv) a negative correlation between FP and the mass of domestic entrepreneurs.

\footnotetext{
${ }^{20}$ These statements take into account for the effect of input availability on foreign presence. We can verify that FP increases with $\frac{\Lambda_{M}^{1-\sigma}}{\Lambda_{D}^{1-\sigma}}$ as long as the latter is less than $1+F_{M}$, which is verified under partial technology adoption.
} 
The same correlations are generated by changes in the relative exogenous efficiency of the foreign technology $\frac{\lambda_{M}^{1-\varepsilon}}{\lambda_{D}^{1-\varepsilon}}$ and by changes in the relative mass of foreign entrepreneurs $\frac{L^{*}}{L}$.

Points i) and ii) imply that changes in structural parameters generate a positive correlation between foreign presence and the average labor productivity of suppliers. Points iii) and iv) show that changes in the same structural parameters generate correlations between domestic firm survival and technology adoption and the extent of foreign presence in the economy. ${ }^{21}$

The link between foreign presence and these key indicators of domestic industrial performance has been the focus of an extensive literature. Empirical studies generally regress a measure of the productivity of domestic firms on a sector-level measure of foreign presence (typically the share of foreign firms in output) in the sector the domestic firms operate (horizontal spillovers) or in downstream industries (vertical spillovers). Some clear patterns arise from this extensive body of work.

First, foreign presence tends to be related to improvements in the productivity of domestic firms in upstream industries. This result has been established by Javorcik (2004) with a panel of Lithuanian firms. She uses time-varying sector-specific measures of foreign presence in a specification where supplier TFP is in differences (both first- and long-) to remove firm fixed effects. She finds that a one-standarddeviation increase in foreign presence is associated with a $15 \%$ increase in supplier productivity. A number of other works confirms this result qualitatively (e.g. see the survey in Alfaro and RodriguezClare, 2004).

Second, the evidence on horizontal spillovers is mixed. ${ }^{22}$ For developing countries, a large group of studies has found consistently negative effects. One example is Aitken and Harrison (1999) for the Venezuelan manufacturing industry. Using panel plant-level data in first- and long-differences, they find that domestic firms in sectors with larger multinational presence have lower TFP than those in sectors with less foreign presence (a 10\% increase in foreign presence reduces domestic firm TFP by 2.67 percentage points). In the case of developed economies, results are often not statistically significant (although some studies find positive and significant effects, e.g. Keller and Yeaple, 2009). There appears to be a role for firm heterogeneity: firms with high abilities ("absorptive capacity", following Cohen and Levin, 1990) tend to improve their performance following multinational entry, whereas foreign presence is detrimental to firms that lack such capacity. ${ }^{23}$ A handful of papers show that this heterogeneity involves foreign firms. An example is Sabirianova et al. (2005) who use panel data from manufacturing firms in the Czech Republic and Russia and find that the productivity advantage associated with being a foreign firm increases with the share of other foreign firms in total output. ${ }^{24}$

\footnotetext{
${ }^{21}$ Starting from an equilibrium with full technology adoption, the changes in the structural parameters do not affect input costs. In this case, a decrease in the foreign entry costs $F_{M N E}$ increases foreign presence and decreases $\Phi_{M}$, leading to both lower technology adoption and firm survival.

${ }^{22}$ In the survey by Gorg and Greenaway (2004), 33 out of 40 papers find either negative or not statistically significant effects.

${ }^{23}$ Gorg and Greenaway (2004) survey this aspect of empirical work.

${ }^{24}$ Aitken and Harrison (1999) find that plants with foreign equity receive positive spillovers from foreign firms. Liu (2008) replicates these results for China.
} 
The bulk of the empirical literature takes a reduced-form approach which is generally not informative of the underlying mechanisms driving the results. ${ }^{25}$ We propose a theoretical mechanism through which variables on both sides of the equation respond to changes in structural parameters that are unobserved by econometricians. In particular, technological incompatibilities tend to naturally generate the coexistence of positive vertical spillovers and heterogeneous horizontal spillovers. They also rationalize positive externalities among multinational firms.

To link our results with the findings in the empirical literature, we need to say a few words on the practical aspects of productivity measurement. If physical output is not observed and firm-specific prices are unavailable, which is generally the case, the measure of output most commonly used is sales deflated using industry-wide price indices. It is well known that this procedure can generate biases in the productivity estimates, especially in differentiated product industries. ${ }^{26}$ Also, in our model, externalities among downstream firms come from changes in the availability of intermediate varieties, affecting the input price index $\Lambda_{T}$. They do not affect firm efficiency, which is given by the $\Phi$ 's (although it would be straightforward to incorporate efficiency gains associated with the M-technology into the model). Nevertheless, most available studies have information on total expenditure and use industrywide deflators (typically, producer price indices) to proxy for physical quantities of inputs. In this case, changes in input prices are unlikely to be properly accounted for and are likely to show up in the residual of the estimated production function, thus affecting measured productivity. It is then likely that the effects that we highlight affect the empirical measures of horizontal spillovers. ${ }^{27}$

A recent paper by Kee (2011) addresses these two issues and provides a set of empirical results closest to our theory. Her data on the Bangladeshi garment industry allow her to observe which domestic firms share suppliers with MNEs and to construct a firm-specific measure of "sibling foreign presence". For each domestic firm, this measure gives the share in industry capital of all foreign firms that source from at least one common supplier with the firm. She uses a within estimator and has access to firm-specific prices and the number of input suppliers (both local and foreign proxied by imports). She finds that sibling foreign presence has a significant effect on domestic firm productivity, while the effect of industry foreign presence (traditional definition) it not significant. Consistently with our theory, she finds that sibling FDI presence affects domestic productivity by expanding the availability of intermediate varieties. Interestingly, in a placebo experiment were siblings are assigned randomly, she finds no effect of sibling foreign presence. This suggests a selection mechanism, which can be rationalized by our model. ${ }^{28}$

\footnotetext{
${ }^{25}$ An exception is Kugler (2006), who motivates his empirical analysis with a dynamic model with externalities where capital accumulation by foreign firms increases the productivity of domestic firms. Another exceptions are Kee (2011) and Alfaro and Chen (2012) who uses a structural approach to quantify the importance of spillover versus selection effects.

${ }^{26}$ See Katayama et al. (2009) and Melitz (2000), who show that, with product differentiation, measurement problems might imply that measured productivity reflects markups instead of firm efficiency.

${ }^{27}$ Halpern et al. (2009) use the case of imported inputs to study how changes in input prices affect empirical TFP measures. Katayama et al. (2009) discuss another channel and show that changes in input prices can affect markups (through changes in marginal costs), and therefore show up as changes in measured productivity.

${ }^{28}$ Kee (2011) also takes an IV approach that uses the everything-but-arms initiative as a shock to foreign presence (arguing that it was unexpected by the firms). The EBA initiative provides free access to the EU for products from 48 developing countries, including Bangladesh. Rules of origin apply to the tariff cuts, prompting foreign firms targeting the
} 


\subsection{General equilibrium: income and occupational choice}

The general equilibrium of the model is characterized by a system comprised of equations (3) to (7) plus the following labor market clearing condition:

$$
L=\rho E+L \Phi_{D}^{-k}+L F_{M} \Phi_{M}^{-k}+L^{*} F_{M N E} \Phi_{M N E}^{-k}
$$

The first term on the right-hand side is the amount of inputs (labor and other) used in the downstream industry. This term includes total employment in the upstream sector plus the mass of upstream entrepreneurs $(\beta \rho E)$, plus labor corresponding to variable labor inputs (excluding fixed costs) in the downstream sector $(1-\beta) \rho E$. The second term corresponds to the number of domestic entrepreneurs in the downstream sector. The third and fourth terms correspond to the fixed costs incurred by upgrading firms and multinationals. ${ }^{29}$

This equation pins down total income $E$. After incorporating equations for thresholds (12), (13) and (14) into (16), we obtain that total income is proportional to labor income (which corresponds to population $L$ after normalizing the wage to unity):

$$
\frac{E}{L}=\frac{k}{k-\rho}
$$

In other words, foreign entry and technology adoption do not affect the share of income from entrepreneurship. This property is a consequence of the assumption that productivity is Pareto distributed. This would not hold in a more general case.

\section{Welfare effects from openness to FDI}

We now look at the welfare effects from FDI openness, comparing the equilibrium with multinationals to that where foreign entry is prohibitively costly $\left(F_{M N E}=\infty\right)$, labeled "autarky" for simplicity. We compare the real wage $\frac{1}{P}$ in both situations (the nominal wage is normalized to one). Our measure of welfare is $\frac{P}{P_{A}}$ : the ratio of the price index in the open economy to the one under autarky. As discussed above, the same measure applies to changes in real income per capita $\frac{E}{L P}$.

We consider three cases: no technological incompatibilities, ${ }^{30}$ technological incompatibilities with no technology adoption (type 1) and technological incompatibilities and technology adoption (type 2).

In the first case, in which inputs are not specific to a particular technology, welfare gains are a

EU to increase their level of local sourcing. Kee argues that the EBA has not directly affected domestic firm productivity, thereby providing an exclusion restriction.

${ }^{29}$ By Walras law, this implies a balance of payments equilibrium. It can be achieved if we assume that profits generated by foreign firms stay in the country. An alternative assumption would be that local entrepreneurs engage in FDI abroad (with their intermediate goods to produce abroad being procured there). At a symmetric equilibrium, their profits would equal those made by foreigners in the home country.

${ }^{30}$ When inputs are not specific to a particular technology, the mass of suppliers is constant and does not depend on foreign entry. This case is therefore equivalent to setting $\beta=0$, i.e. assuming that labor is the only input. 
simple function of foreign presence (FPS) and the Pareto coefficient of the ability distribution:

$$
\frac{P}{P_{A}}=(1+F P S)^{-\frac{1}{k}}
$$

(proof in the appendix). In a recent article, Arkolakis, Costinot and Rodriguez-Clare (2012) show that welfare gains from trade can be reduced to a simple function of the share of consumption of domestic goods for a broad class of models. This expression is similar to the one in their heterogeneous firms specification, with output-weighted foreign presence instead of the ratio of imports to the consumption of domestic goods. This formula also resembles the one in Ramondo and Rodriguez-Clare (2010), who extend the Eaton and Kortum (2002) model to include multinational production.

When inputs are specific to each technology and when no domestic firm adopts the foreign technology (type 1), the formula becomes:

$$
\frac{P}{P_{A}}=(1+F P S)^{-\frac{1}{k}+\frac{\beta}{\varepsilon-1}}
$$

Conditional on foreign presence, the decrease in the final good price index is lower than in the first case. The larger the share of technology-specific inputs in downstream production $\beta$, the smaller the welfare gains ceteris paribus. Assuming that $\frac{k \beta}{\varepsilon-1}<1$ (Proposition 1), welfare gains from foreign entry are positive despite technological incompatibilities.

In the general case with technological incompatibilities and technology adoption in both industries (type 2), welfare gains depend not only on foreign presence but also on the share of domestic firms adopting the M-technology:

$$
\frac{P}{P_{A}}=(1+F P S)^{-\frac{1}{k}+\frac{\beta}{\varepsilon-1}}\left[1+(\Lambda-1) S_{M}\right]^{-\frac{1}{k}+\frac{\beta}{\varepsilon-1}}\left[1-S_{M}\right]^{-\frac{\beta}{\varepsilon-1}}
$$

where $\Lambda \equiv \frac{\Lambda_{M}^{1-\sigma}}{\Lambda_{D}^{1-\sigma}}$ is the cost advantage of the M-technology and $S_{M}=\left(\frac{\Phi_{M}}{\Phi_{D}}\right)^{-k}$ refers to the fraction of domestic firms adopting the foreign technology. Foreign presence and the share of consumption in Dtechnology goods are no longer a sufficient statistic for welfare gains: technology adoption by domestic firms may alter these gains. ${ }^{31}$ In a stable equilibrium, we can show that the lower the foreign entry and technology adoption costs, the higher the welfare (see appendix). However, other things being equal, a larger share of technology-specific inputs in production lowers the welfare gains from foreign entry and technology adoption.

Under the assumption that the foreign technology is "superior", we can also make a comparison with equilibria with full technology adoption (type 3). More precisely, we assume that, with an equal number of suppliers for each technology, profits are larger using the foreign technology. Equivalently, the gain in variable costs in the upstream industry are assumed to be larger than the extra fixed costs

\footnotetext{
${ }^{31}$ The comparison depends on the extent and the gains from technology adoption. There are cases where welfare gains are smaller than $(1+F P S)^{-\frac{1}{k}+\frac{\beta}{\varepsilon-1}}$ and cases where gains are larger. Gains are larger only when $\Lambda$ is sufficiently large.
} 
in the downstream industry: ${ }^{32}$

$$
M \succ D \Longleftrightarrow\left(\frac{\lambda_{M}^{1-\sigma}}{\lambda_{D}^{1-\sigma}}\right)^{\beta}>1+F_{M}
$$

In this case (see appendix), welfare gains are always larger in an equilibrium with full technology adoption (type 3) compared to no or partial technology adoption (type 1 and 2) when there is multiplicity in equilibria. The above assumption does not preclude the existence of such Pareto-inferior equilibria as shown in Proposition 1 (since it does not impose any restriction on $F_{M N E}$ ). Switching from one equilibrium to another requires the coordination of plants in both industries. In that sense, technological incompatibilities act as a barrier to technology adoption.

\section{A simple quantitative illustration}

Although our model is highly stylized, we can use empirically relevant parameters to provide a simple quantitative illustration of the welfare effects of FDI with technological incompatibilities.

The simplicity of the welfare formulae implies that we only need values for a small set of parameters. These are: the shape parameter of the Pareto distribution of abilities $k$, the elasticities of substitution $\sigma$ and $\varepsilon$ and the share of technology-specific inputs in downstream production $\beta$. For all cases, we also need figures for the share of output produced by foreign firms (which determines FPS).

Although it is difficult to estimate the shape of productivity distributions, it is relatively straightforward to estimate the shape of firm-size distributions. In the model, sales are proportional to $\Phi^{\sigma-1}$, which implies that firm size follows a Pareto distribution with shape parameter $\frac{k}{\sigma-1}$. Existing estimates of this coefficient generally lie between 1 and 1.5 (see Axtell, 2001; Helpman et al., 2004). We choose $\frac{k}{\sigma-1}=1.25$, as in Burstein and Monge-Naranjo (2009). Estimates of elasticities of substitution vary substantially across industries (Broda and Weinstein, 2006). To take a stand, we use $\sigma=\varepsilon=4$, which is close to the median estimate by Broda and Weinstein (2006) and the main estimate by Bernard et al. (2003). We stress that the conclusions derived here are not sensitive to this choice. Concerning $\beta$, US input-output tables (BEA) show that the total share of intermediate goods in production is approximately one half on average (Fally, 2012). To provide an illustration, we use a benchmark value $\beta=0.25$ assuming that, on average, half of intermediate goods are technology specific. Foreign firm output shares vary significantly across markets and industries. Ramondo and Rodriguez-Clare (2010) report that gross output value by foreign firms as a share of GDP in OECD countries varies between $6 \%$ (Japan) and 58\% (Portugal). Javorcik (2004) reports FDI shares of 31.5\% on average for Lithuania (with values between $6.6 \%$ and $59.8 \%$ across manufacturing industries). Aitken and Harrison (1999) report FDI shares of employment between $0 \%$ and $35 \%$ across industries in Venezuela. Given these figures, we use a value of $25 \%$.

We analyze the three above cases in the same order. In the first case with no incompatibilities,

\footnotetext{
${ }^{32}$ Profits associated with the technology $T$ can be written: $A \Lambda_{T}^{1-\sigma}$ where $A$ is an entrepreneur-specific profit shifter. The definition of "superiority" means that for any entrepreneur: $A \Lambda_{D}^{1-\sigma}>1 \Longrightarrow A \Lambda_{M}^{1-\sigma}>A \Lambda_{M}^{1-\sigma}+F_{M}$ as long as the relative number of suppliers is the same. This condition is equivalent to condition (20) in the text.
} 
welfare gains are given by equation (17). $25 \%$ of output produced by foreign firms $(\mathrm{FPS}=0.33)$ implies a $8.0 \%$ increase in real wages.

In the second case with technological incompatibilities $(\beta=0.25)$, but no technology adoption by downstream domestic firms, the relevant equation is (18). With $25 \%$ of output produced by multinationals, we obtain an increase in the real wage of $5.4 \%$. The difference compared with the previous case is large and not sensitive to the choice of the elasticity of substitution, although it crucially depends on the difference between $\beta$ and $\frac{\sigma-1}{k}$. When the share of technology-specific intermediate goods is instead $\beta=0.5$, implied welfare gains are reduced to $2.9 \%$.

The third case implies that, when foreign entry triggers technology adoption by downstream domestic firms, having data on foreign presence is not sufficient to compute welfare gains. It also requires information on technology adoption which is generally unavailable. One possibility in line with our theory is to identify upgrading firms as those that share suppliers with foreign firms. Kee (2011) finds this proportion to be $52 \%$ for the Bangladeshi woven industry, where foreign firms are largely present, and $15 \%$ for the non-woven sector. These figures suggest that technology upgrading may concern a large fraction of firms. Quantitatively, welfare implications also crucially depend on the productivity gains from the use of the foreign technology. We assume as before that $25 \%$ of output is produced by foreign firms and that $25 \%$ of domestic firms adopt the foreign technology. If the size increase related to the adoption of the foreign technology is less than $\Lambda-1=56 \%$, implied welfare gains (equation 19) are less than without technology adoption, i.e. less than $5.4 \%$. If instead the size increase is larger than $120 \%$, welfare gains are larger than those without technological incompatibilities $(8.0 \%) .{ }^{33}$

\section{Extension: intermediate goods trade}

We now discuss how the possibility of importing intermediate goods of the M-type affects the analysis. For simplicity we focus on a partial equilibrium set-up where wages are exogenous. ${ }^{34}$ Assume there is an exogenous mass $n_{F}$ of foreign suppliers able to supply M-type inputs to downstream firms using the M-technology, subject to an iceberg trade cost $\tau>1$. The price index of M-type inputs becomes: $\Lambda_{M}=\left(n_{M}+\tau^{1-\varepsilon} n_{F}\right)^{\frac{1}{1-\varepsilon}} \lambda_{M}$ (imports imply that it is bounded above: $\Lambda_{M}<\lambda_{M} \tau n_{F}^{\frac{1}{1-\varepsilon}}$ ).

Downstream equilibrium conditions (equations 5,6 and 7) remain the same and, given relative input costs, so does the solution for the downstream industry thresholds. Concerning the upstream industry, the free-entry equations (3) and (4) must be verified as long as both types of suppliers coexist. Equations (8) and (9) have to be verified for $n_{M}+\tau^{1-\varepsilon} n_{F}$ instead of $n_{M}$. However, the solution for the relative availability of inputs are also unchanged: equation (10) is unaffected as long as the upperbound in $\Lambda_{M}$ is not reached.

There is a difference, however, in terms of total employment in the local upstream industry. Although the total measure of input varieties $n_{D}+n_{M}+\tau^{1-\varepsilon} n_{F}$ remains constant, the mass of local

\footnotetext{
${ }^{33}$ Note that the model can be calibrated to match these two examples.

${ }^{34} \mathrm{~A}$ full general equilibrium model would also require specific assumptions to retrieve the trade balance. The conclusions obtained from such model would depend on the specific assumptions made about the type of firms that can export, which is outside the scope of the paper.
} 
suppliers $n_{D}+n_{M}$ is smaller than in the benchmark case and now depends on the demand for M-type inputs, affected by trade $\operatorname{costs} \tau$ and the availability of imported inputs $n_{F}$.

Previous work has looked into how the potential of multinational firms to create linkages when trade in inputs is allowed for. Alfaro and Rodriguez-Clare (2004) empirically define the "linkage coefficient" of MNEs as the value of inputs both domestically per unit of labor hired locally. In this simple extension

of our model, this measure is an increasing function of the ratio $\frac{n_{M}}{n_{M}+\tau^{1-\varepsilon} n_{F}}$. It depends on domestic technology adoption. When the local supplier base is mainly oriented towards the domestic technology, an increase in foreign presence implies larger imports and smaller overall demand for the local upstream industry. When, on the contrary, foreign entry is accompanied by widespread technology adoption by domestic downstream and upstream firms, the share of imported inputs is low at the resulting equilibrium. These results are not identical to, but resemblant of, those in Rodriguez-Clare (1996) that suggest that underdeveloped regions attract multinationals with low linkage potential. A decrease in transport costs reduces, ceteris paribus, the linkage coefficient. However, imports reduce the price index of M-type inputs and may also trigger technology adoption by downstream domestic firms. This can increase the demand for M-type inputs and foster technology adoption by local suppliers.

\section{Concluding remarks}

The effects of foreign direct investment on the development of host economies are a matter of ongoing debate. In this paper we develop a model around the key assumption of "technological incompatibilities": as suggested by empirical evidence, foreign firms are assumed to operate more advanced technologies which also require different types of inputs. These differences in technologies affect the nature of backward and forward linkages between foreign firms and local suppliers. In cases where productive efficiency is determined by the availability of intermediate inputs, supplier technology choices determine the relative costs associated with each technology.

Our analysis delivers novel insights into the impact of foreign entry on domestic firms' productivity, technology adoption, survival, and welfare. Technological incompatibilities create strategic complementarities among plants using the same technology: the larger the share of plants operating a given technology, the wider the availability of compatible intermediate inputs, reducing unit costs. Since technology adoption is costly, firm heterogeneity plays a natural role: only the most productive firms find it optimal to adopt the foreign technology and to benefit from the decrease in the cost of intermediate inputs. Firms that do not engage in foreign technology adoption suffer from increased competition and from a reduction in the availability of inputs compatible with the domestic technology. The least productive ones are forced out. We show that technological incompatibilities condition the welfare effects of FDI.

The predictions of the model are consistent with extensive empirical evidence on FDI spillovers. While most of available evidence is in direct and reduced-form, our theory provides a framework which we hope could guide future empirical research. 


\section{References}

[1] Alfaro, L. and Chen, M. (2012), "Selection, Reallocation, and Spillover: Identifying the Sources of Gains from Multinational Production," NBER Working Paper 18207.

[2] Alfaro, L. and Rodriguez-Clare, (2004) "Multinationals and Linkages: An Empirical Investigation," Economia, Vol. 4, Nr 2.

[3] Alfaro, L., Kalemli-Ozcan, S., Chanda, A. Sayek, S. (2010) "Does Foreign Direct Investment Promote Growth? Exploring the Role of Financial Markets on Linkages," Journal of Development Economics 91(2), 242-256.

[4] Aitken, B. and Harrison, A. (1999), "Do Domestic Firms Benefit from Direct Foreign Investment? Evidence from Venezuela," American Economic Review, Vol. 89.

[5] Arkolakis, K., Costinot, A. and Rodriguez-Clare, A. (2012), "New Trade Models, Same Old Gains?" American Economic Review, 102(1), pp. 94-130.

[6] Axtell, R. (2001), "Zipf Distribution of U.S. Firm Sizes,", Science 293, nr.5536, 1818 - 1820.

[7] Barba-Navaretti, G. and Venables, A. (2004), "Multinational Firms in the World Economy," Princeton University Press, Princeton.

[8] Broda, C. and Weinstein, D., "Globalization and the Gains from Variety," Quarterly Journal of Economics, 121(2), 541-585.

[9] Burstein, A. and Monge-Naranjo, A. (2009), "Foreign Know-How, Firm Control, and the Income of Developing Countries," Quarterly Journal of Economics, 124(1), 149-195.

[10] Carluccio, J. and Fally, T. (2008), "Multinationals, Technological Incompatibilities, and Spillovers", PSE Working Paper 63-2008.

[11] Cohen, W. and Levin, L. (1990) "Absorptive capacity: A new perspective on learning and innovation", Administrative Science Quarterly, 35(1), 128-152.

[12] Ciccone, A. and Matsuyama, K. (1996) "Start-up Costs and Pecuniary Externalities as Barriers to Economic Development", Journal of Development Economics, Vol. 49 Issue 1.

[13] Eaton J., Kortum, S. (2002), "Technology, Geography and Trade," Econometrica, 70(5),1741-1779.

[14] Ethier, W. (1982), "National and international returns to scale in the modern theory of international trade," American Economic Review Vol. 72, Issue 3, 389-405.

[15] Fally, T. (2012), "Production Staging: Measurement and Evidence", mimeo, University of Colorado.

[16] Gorg, H. and Greenaway, D. (2004), "Much ado about nothing? Do domestic firms really benefit from foreign direct investment?" World Bank Research Observer, 19(2), 171-197.

[17] Halpern, L., Koren, M., and Szeidl, A. (2009), "Imported Inputs and Productivity," CeFiG Working Papers 8, Center for Firms in the Global Economy.

[18] Helpman, E., Melitz, M. and Yeaple, S. (2004), "Export versus FDI with heterogeneous firms," American Economic Review, 94, 300-316. 
[19] Javorcik, B.(2004), "Does Foreign Direct Investment Increase the Productivity of Domestic Firms? In Search of Spillovers through Backward Linkages," American Economic Review, Vol. 94.

[20] Javorcik, B., Keller, W., Tybout, J. (2006), "Openness and industrial response in a Wal-Mart world: a case study of Mexican soaps, detergents, and surfactant producers," World Bank Policy Research Working Paper 3999.

[21] Katayama, H., Lu, S. and Tybout, J. (2009), "Firm-level productivity studies: Illusions and a solution," International Journal of Industrial Organization, 27(3), 403-413.

[22] Kee, H. L. (2011) "Uncovering Horizontal Spillovers: When Foreign and Domestic Firms Share Common Local Input Suppliers," mimeo, The World Bank.

[23] Keller, W. (2009), "International Trade, Foreign Direct Investment, and Technology Spillovers," Handbook of the Economics of Innovation, B. Hall and N. Rosenberg (eds), North-Holland.

[24] Keller, W. and Yeaple, S. (2009) "Multinational Enterprises, International Trade, and Productivity Growth: Firm-level Evidence from the United States," Review of Economics and Statistics, 91(4): 821-831.

[25] Kugler, M (2006), "Spillovers from Foreign Direct Investment: Within or Between Industries?," Journal of Development Economics, Vol. 80, Issue 2.

[26] Lipsey, R. (2002) "Home and Host Country Effects of FDI," NBER Working Papers 9293.

[27] Lin, P. and Saggi, K. (2007) "Multinational, Exclusivity, and Backward Linkages," Journal of International Economics, Vol. 71, pp. 206-220.

[28] Liu, Z. (2006), "Foreign direct investment and technology spillovers: Theory and evidence," Journal of Development Economics, 85 (1-2), 176-193.

[29] Lucas, R. (1978) "On the Size Distribution of Business Firms," Bell Journal of Economics, 9, 508-523.

[30] Markusen, J. and Ethier, W. (1995), "Multinationals, Technology Diffusion, and Trade," Journal of International Economics, 14 (1-2), 1-28.

[31] Markusen, J. and Venables, A.(1999), "Foreign direct investment as a catalyst for industrial development," European Economic Review, Vol. 43.

[32] Melitz, M. (2000), "Firm Productivity Estimation in Differentiated Product Industries," mimeo.

[33] Melitz, M. (2003), "The Impact of Trade on Intra-Industry Reallocations on Aggregate Industry Productivity," Econometrica, Vol. 71, Issue 6.

[34] OECD (2002), "Encouraging Linkages Between Small and Medium-sized Companies and Multinational Entreprises," OECD, Paris.

[35] Ramondo, N. and Rodriguez-Clare, A. (2010), "Trade, Multinational Production, and the Gains from Openness," mimeo, Penn State University.

[36] Redding, S. (2011) "Theories of Heterogeneous Firms and Trade," Annual Review of Economics. 
[37] Rodriguez-Clare, A. (1996) "Multinationals, Linkages, and Economic Development," American Economic Review, Vol. 86.

[38] Sabirianova, K., Svejnar, J. and Terrell, K. (2005) "Distance to the Efficiency Frontier and Foreign Direct Investment Spillovers," Journal of the European Economic Association Papers and Proceedings, 3(2-3), 576-586.

[39] UNCTAD (2001), "World Investment Report 2001: Promoting Linkages," United Nations.

[40] UNCTAD (2007), "Food Safety and Environmental Requirements in Export Markets - Friend or Foe for Producers of Fruit and Vegetables in Asian Developing Countries?," United Nations.

[41] UNCTAD (2008), "World Investment Report 2008: Transnational Corporations, and the Infrastructure Challenge," United Nations.

\section{Appendix}

\section{Section 3: Analytical results for type-1 and type-3 equilibria}

- Section 3.2. When $\frac{\Lambda_{M}^{1-\sigma}}{\Lambda_{D}^{1-\sigma}}<1$, there is no technology adoption by domestic firms $\left(\Phi_{M}=\infty\right)$. In this case: $\Phi_{D}=\left(\frac{k \sigma}{k-\sigma+1} \frac{L}{E}\right)^{\frac{1}{k}}\left[1+\frac{L^{*}}{L} F_{M N E}^{1-\frac{k}{\sigma-1}}\left(\frac{\Lambda_{M}^{1-\sigma}}{\Lambda_{D}^{1-\sigma}}\right)^{\frac{k}{\sigma-1}}\right]^{\frac{1}{k}}$, the expression for $\Phi_{M N E}$ is the same as in the main text. The ratio of mass of firms becomes: $\frac{\widetilde{N}_{M}}{\widetilde{N}_{D}}=\frac{L^{*}}{L}\left(\frac{\Lambda_{M}^{1-\sigma}}{\Lambda_{D}^{1-\sigma}}\right)^{\frac{k}{\sigma-1}-1} F_{M N E}^{1-\frac{k}{\sigma-1}}$.

When $\frac{\Lambda_{M}^{1-\sigma}}{\Lambda_{D}^{1-\sigma}}>\left(1+F_{M}\right)$, all domestic firms adopt the foreign technology $\left(\Phi_{M}=\Phi_{D}\right.$ and $\left.\tilde{N}_{D}=0\right)$. In this case:

$$
\begin{aligned}
\Phi_{M} & =\left(\frac{k \sigma}{k-\sigma+1} \frac{L\left(1+F_{M}\right)}{E}\right)^{\frac{1}{k}}\left[1+\frac{L^{*}}{L}\left(\frac{F_{M N E}}{1+F_{M}}\right)^{1-\frac{k}{\sigma-1}}\right]^{\frac{1}{k}} \\
\Phi_{M N E}^{\sigma-1} & =\frac{F_{M N E}}{1+F_{M}} \Phi_{M}^{\sigma-1}
\end{aligned}
$$

- Section 3.3. The equilibrium with no technology adoption (type 1) is characterized by:

$$
\frac{\Lambda_{M}^{1-\sigma}}{\Lambda_{D}^{1-\sigma}}=\left(F_{M N E}^{1-\frac{k}{\sigma-1}} \frac{\lambda_{M}^{1-\varepsilon}}{\lambda_{D}^{1-\varepsilon}} \frac{L^{*}}{L}\right)^{\frac{\beta(\sigma-1)}{\varepsilon-1-\beta k}}<1 \quad \text { and } \quad \frac{\widetilde{N}_{M}}{\widetilde{N}_{D}}=\left(F_{M N E}^{1-\frac{k}{\sigma-1}} \frac{\lambda_{M}^{1-\varepsilon}}{\lambda_{D}^{1-\varepsilon}} \frac{L^{*}}{L}\right)^{\frac{\varepsilon-1-\beta(\sigma-1)}{\varepsilon-1-\beta k}} \frac{\lambda_{D}^{1-\varepsilon}}{\lambda_{M}^{1-\varepsilon}}
$$

With full technology adoption (type 3 with $\tilde{N}_{D}=n_{D}=0$ ), we have:

$$
\tilde{N}_{M}=\left[\frac{k}{k-(\sigma-1)}\left(L F_{M}^{1-\frac{k}{\sigma-1}}+L^{*} F_{M N E}^{1-\frac{k}{\sigma-1}}\right)\left(\frac{E}{\sigma}\right)^{\frac{k}{\sigma-1}-1}\right]^{\frac{\sigma-1}{k}} \Lambda_{M}=\left(\frac{\varepsilon}{\varepsilon-1} \lambda_{M}\left(\frac{\beta \rho E}{\varepsilon}\right)^{\frac{1}{1-\varepsilon}}\right)^{\beta}
$$

\section{Proof of Proposition 1:}

( $i$ ) A type-1 equilibrium is defined as an equilibrium with no technology adoption by domestic firms. This situation can arise if and only if $\frac{\Lambda_{M}^{1-\sigma}}{\Lambda_{D}^{1-\sigma}}<1$. In this case, the downstream curve given by expression (15) simplifies:

$$
\frac{\widetilde{N}_{M}}{\widetilde{N}_{D}}=\frac{L^{*}}{L}\left(\frac{\Lambda_{M}^{1-\sigma}}{\Lambda_{D}^{1-\sigma}}\right)^{\frac{k}{\sigma-1}-1} F_{M N E}^{1-\frac{k}{\sigma-1}}
$$


Combining with equation (15) that characterizes the upstream industry, we obtain that $\frac{\Lambda_{M}^{1-\sigma}}{\Lambda_{D}^{1-\sigma}}<1$ if and only if: $F_{M N E}^{\frac{k}{\sigma-1}-1}>\frac{\lambda_{M}^{1-\varepsilon}}{\lambda_{D}^{1-\varepsilon}} \frac{L^{*}}{L}$. The slope of the upstream curve (in log), i.e. the elasticity of the relative advantage of the foreign technology w.r.t $\frac{\widetilde{N}_{M}}{\widetilde{N}_{D}}$ is given by $\frac{\widetilde{\beta}}{1-\widetilde{\beta}}$ while the slope of the downstream curve is given by the exponent of $\frac{\Lambda_{M}^{1-\sigma}}{\Lambda_{D}^{1-\sigma}}$ in equation $(21): \frac{k}{\sigma-1}-1$. Stability is ensured when the downstream curve is flatter, which is equivalent to our assumption $\frac{\beta k}{\varepsilon-1}<1$. Moreover, there is a unique intersection since both curves are log-linear in this case.

(ii) Lemma 1 below ensures that the downstream curve increases faster in the interval $\frac{\Lambda_{M}^{1-\sigma}}{\Lambda_{D}^{1-\sigma}} \in\left(1,1+F_{M}\right)$ than in the interval $(0,1)$; i.e. when there is technology adoption. We can deduce that on the internal $\left(1,1+F_{M}\right)$ the downstream curve will be strictly above the curve given by equation (21) above. In turn, if the upstream curve is below the curve given by equation (21), we obtain a sufficient condition for the absence of a type-2 equilibrium. Using expression (10) for the upstream curve, this happens when $F_{M N E}^{\frac{k}{\sigma-1}-1}<\frac{\lambda_{M}^{1-\varepsilon}}{\lambda_{D}^{1-\varepsilon}} \frac{L^{*}}{L}\left(1+F_{M}\right)^{\frac{(\varepsilon-1)-\beta k}{\sigma-1}}$. In the case where $F_{M N E}^{\frac{k}{\sigma-1}-1}>\frac{\lambda_{M}^{1-\varepsilon}}{\lambda_{D}^{1-\varepsilon}} \frac{L^{*}}{L}\left(1+F_{M}\right)^{\frac{(\varepsilon-1)-\beta k}{\sigma-1}}$, the uniqueness of stable type-2 equilibria derives from Lemma 1. Using Lemma 1, we know that the slope of the downstream curve (in log) is first decreasing and then increasing (or always increasing) over the interval $\frac{\Lambda_{M}^{1-\sigma}}{\Lambda_{D}^{1-\sigma}} \in\left(1,1+F_{M}\right)$. Given that the upstream curve is linear (in log), it implies that the upstream curve cuts the downstream curve at three points at most: first from above, then from below, and finally from above. If the upstream curve cuts the downstream curve only twice, it would be once from below and once from above. In any case, there is at most one stable equilibrium where the upstream curve cuts the downstream curve from below.

(iii) For any parameter values, there exists a stable equilibrium where the foreign technology is the only one being used. Foreign firms, by assumption, do not switch to the domestic technology. Moreover, the relative advantage of using the foreign technology would be infinite in this case: $\frac{\Lambda_{D}^{1-\sigma}}{\Lambda_{M}^{1-\sigma}}=+\infty$ since all suppliers would adopt the foreign technology and since all downstream firms would require foreigntype inputs. A small deviation of the relative number of suppliers would not change domestic firms' adoption: all prefer the foreign technology as long as $\frac{\Lambda_{M}^{1-\sigma}}{\Lambda_{M}^{1-\sigma}}>1+F_{M}$.

As stated in the text, stability requires the downstream curve to be flatter than the upstream curve around the equilibrium. The upstream curve (in log) has a constant slope (equation 10) with coefficient $\frac{1}{\widetilde{\beta}}-1$. We focus here on the slope of the downstream curve. First we re-write the downstream curve as a function $f(x)$ where $x \equiv \frac{\Lambda_{M}^{1-\sigma}}{\Lambda_{D}^{1-\sigma}}$. This function $f(x)$ is defined for the interval $0<x<1+F_{M}$. The slope of the downstream curve (in $\log$ ) is then given by the elasticity $\frac{\partial \log f(x)}{\partial \log x}$. For $x<1$, this elasticity equals $\frac{k}{\sigma-1}-1$. For $x>1$ (i.e. with partial technology adoption by domestic firms), we show that:

Lemma 1: For $x \equiv \frac{\Lambda_{M}^{1-\sigma}}{\Lambda_{D}^{1-\sigma}} \in\left(1,1+F_{M}\right)$ :

(i) $\frac{\partial \log f(x)}{\partial \log x}>\frac{k}{\sigma-1}-1$.

(ii) $\frac{\partial \log f(x)}{\partial \log x}$ is first decreasing and then increasing in $x$, or always increasing. 
Point $i$ ) implies that $\frac{k}{\sigma-1}-1<\frac{1}{\widetilde{\beta}}-1$ is a necessary condition for the slope of the downstream curve to be flatter than the upstream curve, and therefore a necessary condition for the existence of stable type- 1 and type- 2 equilibria. This is equivalent to the condition $\frac{k \beta}{\varepsilon-1}<1$ imposed in Proposition 1.

Proof of Lemma 1: In addition to $x$, we introduce the notations: $a=\frac{k}{\sigma-1}-1 ; g(x) \equiv F_{M}^{-a}(x-1)^{a}$ and $b \equiv \frac{L^{*}}{L} F_{M N E}^{-a} F_{M}^{a}$. We denote the slope of the downstream curve by $\varepsilon(x) \equiv \frac{\partial \log f(x)}{\partial \log x}$. The proof here focuses on empirically-relevant cases assuming $a<1$. Similar properties can be shown for $a>1 .^{35}$

Point $(i)$ can be shown by writing:

$$
\varepsilon(x)=\frac{a x}{x-1} \frac{1}{1-g(x)}-\frac{a}{x-1} \frac{b\left(\frac{x}{x-1}\right)^{a}}{1+b\left(\frac{x}{x-1}\right)^{a}}>\frac{a x}{x-1}-\frac{a}{x-1}=a
$$

To prove $(i i)$ we first derive $\varepsilon(x)$ to get: $\frac{\partial \varepsilon(x)}{\partial x}=\frac{a}{(x-1)^{2}}[h(x)+m(x)]$, with $h(x)=\frac{a x g(x)}{(1-g(x))^{2}}-\frac{1}{1-g(x)}$ and $m(x)=\left(\frac{b\left(\frac{x}{x-1}\right)^{a}}{1+b\left(\frac{x}{x-1}\right)^{a}}\right)\left(1+\frac{\frac{a}{x}}{1+b\left(\frac{x}{x-1}\right)^{a}}\right)>0$. The remainder of the proof shows that $h(x)+m(x)$ is negative (or null) below a certain threshold in $x$ and positive when $x$ is above this threshold.

When $x$ converges to $1, m(x)$ also converges to 1 . The derivative of $m(x)$ is:

$$
m^{\prime}(x)=-\frac{b\left(\frac{x}{x-1}\right)^{a}}{\left[1+b\left(\frac{x}{x-1}\right)^{a}\right]^{2}} \frac{1}{x-1} \times \frac{a}{x}\left(2-\frac{1-a}{x}\right)
$$

We can see that the derivative is negative, therefore $m(x) \in[0,1]$. Moreover $m(x)$ is convex. To see the convexity of $m(x)$, we can check that the product of the first two terms decreases with $x$ (in absolute value), and the product of the last two terms also decreases with $x$. This implies that $m^{\prime \prime}(x)>0$.

In turn, we can check that $h(x)$ satisfies:

1. $h(x)<-1$ if $x<x_{1}$ where $x_{1}$ is (uniquely) defined by $a x_{1}+g\left(x_{1}\right)=1$. This can be seen after writing:

$$
h(x)+1=\frac{a x g(x)}{(1-g(x))^{2}}-\frac{1}{1-g(x)}+1=\frac{g(x)}{(1-g(x))^{2}}[a x+g(x)-1]
$$

2. $h(x)>0$ if $x>x_{2}$ where $x_{2}$ is defined by $a x_{2} g\left(x_{2}\right)+g\left(x_{2}\right)=1$. This can be seen after writing:

$$
h(x)=\frac{a x g(x)+g(x)-1}{(1-g(x))^{2}}
$$

3. $h(x)$ is convex for for $x \in\left[x_{1}, x_{2}\right]$. Taking the derivative w.r.t. $x$ :

$$
h^{\prime}(x)=\frac{a g(x)}{(1-g(x))^{2}}\left(1+\left[\frac{a x-1}{x-1}\right]+\left[\frac{2}{x-1} \frac{a x g(x)}{1-g(x)}\right]\right)
$$

Since $g(x)$ is increasing in $x$, the term $\frac{a g(x)}{(1-g(x))^{2}}$ is also increasing in $x$. The first term in brackets is increasing if $a<1$. In turn, the derivative of the second term in brackets is:

$$
\frac{a x g(x)}{(1-g(x))^{2}(x-1)^{2}}[a x+g(x)-1]>0 \quad \text { if } \quad x>x_{1}
$$

\footnotetext{
${ }^{35}$ If $a>1, h(x)$ is always larger than -1 and convex, i.e. $h^{\prime \prime}(x) \geq 0$, for all $x>1$. In the case $a>1$, the slope can be always increasing instead of being first decreasing and then increasing.
} 
We now combine our results on $m(x)$ and $h(x)$. Since $m(x)<1$ and $h(x)<-1$ for $x<x_{1}$, point 1. implies that $h(x)+m(x)$ is negative for $x<x_{1}$. Point 2. implies that $h(x)+m(x)$ is positive for $x>x_{2}$ since $m(x)>0$ and $h(x)>0$ for $x>x_{2}$. By continuity of $h(x)$ and $m(x)$, the sum $h(x)+m(x)$ is equal to zero for at least a value of $x^{*} \in\left(x_{1}, x_{2}\right)$. Moreover, on this interval both $m(x)$ and $h(x)$ are convex (point 3. above). The threshold $x^{*}$ is therefore unique (a convex function can switch sign and become positive only once). Since the derivative $\frac{\partial \varepsilon(x)}{\partial x}$ has the same sign as $h(x)+m(x)$, we can conclude that $\frac{\partial \varepsilon(x)}{\partial x}$ is negative for $1<x<x^{*}$ and positive for $x>x^{*}$.

\section{Section 4: Expression for welfare relative to autarky}

Here we present the proof for the general case (equation 19 for type-2 equilibria) but the proof is very similar for other cases (type 1 with or without technological incompatibilities). Expressions for welfare gains can be obtained from the free-entry condition for domestic firms. If at least some domestic firms use the D-technology both in autarky (when $F_{M N E}=\infty$ ) and in open economy, the free-entry equation (5) gives:

$$
\frac{P^{1-\sigma}}{P_{A}^{1-\sigma}}=\frac{\Lambda_{D}^{1-\sigma}}{\Lambda_{A}^{1-\sigma}} \cdot \frac{\Phi_{D}^{\sigma-1}}{\Phi_{A}^{\sigma-1}}
$$

where $P_{A}$ and $\Lambda_{A}$ correspond to the price index of final and intermediate goods in autarky, and $\Phi_{A}$ corresponds to the survival threshold in autarky. Using equation (12), we obtain:

$$
\frac{\Phi_{D}}{\Phi_{A}}=\left[1+F_{M}^{1-\frac{k}{\sigma-1}}\left(\frac{\Lambda_{M}^{1-\sigma}}{\Lambda_{D}^{1-\sigma}}-1\right)^{\frac{k}{\sigma-1}}+\frac{L^{*}}{L} F_{M N E}^{1-\frac{k}{\sigma-1}}\left(\frac{\Lambda_{M}^{1-\sigma}}{\Lambda_{D}^{1-\sigma}}\right)^{\frac{k}{\sigma-1}}\right]^{\frac{1}{k}}
$$

From the free-entry conditions for upstream firms (equation 3), we can show that the mass of suppliers using the D-technology is proportional to the share of sales by firms using the foreign technology. This gives:

$$
\frac{\Lambda_{D}^{1-\sigma}}{\Lambda_{A}^{1-\sigma}}=\left[\frac{1+F_{M}^{1-\frac{k}{\sigma-1}}\left(\frac{\Lambda_{M}^{1-\sigma}}{\Lambda_{D}^{1-\sigma}}-1\right)^{\frac{k}{\sigma-1}}+\frac{L^{*}}{L} F_{M N E}^{1-\frac{k}{\sigma-1}}\left(\frac{\Lambda_{M}^{1-\sigma}}{\Lambda_{D}^{1-\sigma}}\right)^{\frac{k}{\sigma-1}}}{1-F_{M}^{1-\frac{k}{\sigma-1}}\left(\frac{\Lambda_{M}^{1-\sigma}}{\Lambda_{D}^{1-\sigma}}-1\right)^{\frac{k}{\sigma-1}-1}}\right]^{-\widetilde{\beta}}
$$

with $\widetilde{\beta}=\beta \cdot \frac{\sigma-1}{\varepsilon-1}$. We obtain the expression in the text by combining these two expressions above. Foreign presence (FPS), as defined in the main text, is factored out leaving an expression which can be seen as a function of the cost advantage and the fraction of upgrading firms $S_{M}=F_{M}^{1-\frac{k}{\sigma-1}}\left(\frac{\Lambda_{M}^{1-\sigma}}{\Lambda_{D}^{1-\sigma}}-1\right)^{\frac{k}{\sigma-1}-1}$.

\section{Comparative statics in welfare with partial technology adoption (type 2):}

Using and inverting equation (10) describing the relative advantage of the foreign technology as a function of the relative mass of downstream firms, we can simplify the welfare term associated with input prices to get:

$$
\frac{\Lambda_{D}^{1-\sigma}}{\Lambda_{A}^{1-\sigma}}=\left[1+\frac{\Lambda_{M}^{1-\sigma}}{\Lambda_{D}^{1-\sigma}} \frac{\widetilde{N}_{M}}{\widetilde{N}_{D}}\right]^{-\widetilde{\beta}}=\left[1+\frac{\lambda_{D}^{1-\varepsilon}}{\lambda_{M}^{1-\varepsilon}}\left(\frac{\Lambda_{M}^{1-\sigma}}{\Lambda_{D}^{1-\sigma}}\right)^{\frac{1}{\widetilde{\beta}}}\right]^{-\widetilde{\beta}}
$$

Hence welfare gains can be rewritten: 


$$
\frac{P^{1-\sigma}}{P_{A}^{1-\sigma}}=\left[1+F_{M}^{1-\frac{k}{\sigma-1}}\left(\frac{\Lambda_{M}^{1-\sigma}}{\Lambda_{D}^{1-\sigma}}-1\right)^{\frac{k}{\sigma-1}}+\frac{L^{*}}{L} F_{M N E}^{1-\frac{k}{\sigma-1}}\left(\frac{\Lambda_{M}^{1-\sigma}}{\Lambda_{D}^{1-\sigma}}\right)^{\frac{k}{\sigma-1}}\right]^{\frac{\sigma-1}{k}}\left[1+\frac{\lambda_{D}^{1-\varepsilon}}{\lambda_{M}^{1-\varepsilon}}\left(\frac{\Lambda_{M}^{1-\sigma}}{\Lambda_{D}^{1-\sigma}}\right)^{\frac{1}{\widetilde{\beta}}}\right]^{-\widetilde{\beta}}
$$

The partial derivative of the above expression w.r.t. the cost advantage of using the foreign technology $\frac{\Lambda_{M}^{1-\sigma}}{\Lambda_{D}^{1-\sigma}}$ (holding other parameters constant) is zero. In particular, this partial derivative is positive when the downstream curve (equation 15) is above the upstream curve (equation 10) and negative otherwise. This means that the relative cost advantage of the foreign technology maximizes the above expression when it corresponds to the equilibrium relative cost advantage. Applying the envelop theorem, we can see that welfare gains (at equilibrium) decrease with the fixed cost of foreign entry $F_{M N E}$ and the fixed cost of technology adoption $F_{M}$.

\section{Welfare with full technology adoption (type 3) compared to autarky:}

Welfare in type 3: Since there is no firm using the D-technology in type-3 equilibrium, the price index equation is based on the free-entry condition for domestic firms adopting the foreign technology:

$$
\frac{P^{1-\sigma}}{P_{A}^{1-\sigma}}=\frac{\Lambda_{M}^{1-\sigma}}{\Lambda_{A}^{1-\sigma}} \cdot \frac{\Phi_{M}^{1-\sigma}}{\Phi_{A}^{1-\sigma}} \cdot \frac{1}{1+F_{M}}
$$

In terms of threshold, we get:

$$
\frac{\Phi_{M}}{\Phi_{A}}=\left(1+F_{M}\right)^{\frac{1}{k}}\left[1+\frac{L^{*}}{L}\left(\frac{F_{M N E}}{1+F_{M}}\right)^{1-\frac{k}{\sigma-1}}\right]^{\frac{1}{k}}
$$

Since the total number of suppliers remain the same, the relative price of inputs only depends on relative costs of production:

$$
\frac{\Lambda_{M}^{1-\sigma}}{\Lambda_{A}^{1-\sigma}}=\left(\frac{\lambda_{M}^{1-\sigma}}{\lambda_{D}^{1-\sigma}}\right)^{\beta}=\left(\frac{\lambda_{M}^{1-\varepsilon}}{\lambda_{D}^{1-\varepsilon}}\right)^{\widetilde{\beta}}
$$

We thus obtain:

$$
\frac{P^{1-\sigma}}{P_{A}^{1-\sigma}}=\left(\frac{\lambda_{M}^{1-\varepsilon}}{\lambda_{D}^{1-\varepsilon}}\right)^{\widetilde{\beta}}\left(1+F_{M}\right)^{\frac{\sigma-1}{k}-1}\left[1+\frac{L^{*}}{L}\left(\frac{F_{M N E}}{1+F_{M}}\right)^{1-\frac{k}{\sigma-1}}\right]^{\frac{\sigma-1}{k}}
$$

\section{Welfare: full technology adoption (type 3) vs. no or partial technology adoption:}

In a type-2 equilibrium with partial technology adoption, the price index compared to autarky is given by equation (22). Holding other variables constant, the left term in brackets is increasing in the relative advantage of the foreign technology $\frac{\Lambda_{M}^{1-\sigma}}{\Lambda_{D}^{1-\sigma}}$. Hence, given that $\frac{\Lambda_{M}^{1-\sigma}}{\Lambda_{D}^{1-\sigma}}<1+F_{M}$ in a type-2 equilibrium, and given that the second term into bracket (in equation 22) is smaller than one, we obtain:

$$
\frac{P^{1-\sigma}}{P_{A}^{1-\sigma}}<\left[1+F_{M}+\frac{L^{*}}{L} F_{M N E}^{1-\frac{k}{\sigma-1}}\left(1+F_{M}\right)^{\frac{k}{\sigma-1}}\right]^{\frac{\sigma-1}{k}}=\left(1+F_{M}\right)^{\frac{\sigma-1}{k}}\left[1+\frac{L^{*}}{L}\left(\frac{F_{M N E}}{1+F_{M}}\right)^{1-\frac{k}{\sigma-1}}\right]^{\frac{\sigma-1}{k}}
$$

Then, using the assumption that the foreign technology is "superior", i.e. $\left(\frac{\lambda_{M}^{1-\varepsilon}}{\lambda_{D}^{1-\varepsilon}}\right)^{\widetilde{\beta}}\left(1+F_{M}\right)^{-1}>1$, and multiplying by this term, we obtain that the welfare gains in a type-2 equilibrium are smaller than in a type-3 equilibrium as given by equation (23). The comparison to a type-1 equilibrium follows the same logic. In this case, we can even impose a smaller upper bound for $\frac{\Lambda_{M}^{1-\sigma}}{\Lambda_{D}^{1-\sigma}}<1<1+F_{M}$. 